\title{
Nanoparticle-mediated pulmonary drug delivery: state of the art towards efficient treatment of recalcitrant respiratory tract bacterial infections
}

\author{
Zheng Huang $^{1} \cdot$ Sylvia Natalie Kłodzińska ${ }^{1} \cdot$ Feng Wan $^{1}\left[\right.$ [ Hanne Mørck Nielsen ${ }^{1}$
}

Accepted: 1 March 2021 / Published online: 10 March 2021

(c) Controlled Release Society 2021

\begin{abstract}
Recalcitrant respiratory tract infections caused by bacteria have emerged as one of the greatest health challenges worldwide. Aerosolized antimicrobial therapy is becoming increasingly attractive to combat such infections, as it allows targeted delivery of high drug concentrations to the infected organ while limiting systemic exposure. However, successful aerosolized antimicrobial therapy is still challenged by the diverse biological barriers in infected lungs. Nanoparticle-mediated pulmonary drug delivery is gaining increasing attention as a means to overcome the biological barriers and accomplish site-specific drug delivery by controlling release of the loaded drug(s) at the target site. With the aim to summarize emerging efforts in combating respiratory tract infections by using nanoparticle-mediated pulmonary delivery strategies, this review provides a brief introduction to the bacterial infection-related pulmonary diseases and the biological barriers for effective treatment of recalcitrant respiratory tract infections. This is followed by a summary of recent advances in design of inhalable nanoparticlebased drug delivery systems that overcome the biological barriers and increase drug bioavailability. Finally, challenges for the translation from exploratory laboratory research to clinical application are also discussed and potential solutions proposed.
\end{abstract}

Keywords Respiratory tract bacterial infections · Biofilms · Intracellular infections · Chronic pulmonary diseases · Pulmonary drug delivery $\cdot$ Nanotechnology

\section{Introduction}

The respiratory tract is constantly exposed to the external environment, which include exposure to microorganisms (such as bacteria, viruses and fungi) in the air. Respiratory tract infections that may occur as a result of such exposure, if pathogenic microorganisms are not cleared from the lungs upon inhalation, can be categorized into upper respiratory tract infections and lower respiratory tract infections. Among these, the lower respiratory tract infections are particularly problematic, being the top leading cause of death in the developing countries and the third leading cause of deaths

Feng Wan

feng.wan@sund.ku.dk

$\triangle$ Hanne Mørck Nielsen hanne.morck@sund.ku.dk

1 Center for Biopharmaceuticals and Biobarriers in Drug Delivery, Department of Pharmacy, University of Copenhagen, Universitetsparken 2, DK-2100 Copenhagen $\varnothing$, Denmark worldwide [1, 2]. In addition, lower respiratory tract infections are also causing an escalating financial burden to the global healthcare system by the requirement of intensive care. In general, bacteria are the dominant pathogens causing lower respiratory tract infections, though there is increasing evidence of bacterial-viral co-infections and of bacterial infections being secondary to viral infection [3]. This article focuses on the most recent developments in nanoparticlemediated pulmonary drug delivery aiming at efficient treatment of respiratory tract bacterial infections. As for the nanotechnology-based antiviral therapeutics, the readers are referred to a recent review on this topic [4].

In general, lower respiratory tract infections are difficult to treat because microbes reside deep in the respiratory tract, usually embedded in a combination of thick mucus and biofilm. Treatment of such infections with oral and/or intravenously administered antibiotics requires high doses to maintain therapeutic concentrations, because only a small fraction of the administered drugs can access the mucosal side of the lungs from the systemic circulation. In contrast, inhalation of antimicrobials offers targeted drug delivery to 
the primary site of infections, while simultaneously minimizing systemic exposure and associated side effects $[5,6]$. Ensuring high local concentrations of antimicrobials is crucial for effective eradication of antibiotic-sensitive as well as multidrug-resistant pathogens, in both extracellular and intracellular infections. However, inhaled antimicrobials in solution are often rapidly cleared from the lungs or inactivated by metabolic enzymes [7], resulting in short residence times and sub-effective concentrations of antimicrobials. This may further induce the development of antimicrobial resistance $[8,9]$. Poor intracellular bioavailability of many antimicrobials adds to this problem, often leading to failure in the treatment of intracellular infections and the development of antimicrobial drug resistance [10].

For years, the discovery void in new antimicrobials has caused great challenges and compared to the development of new therapeutics based on novel antimicrobial chemical entities, the development of efficient formulations to deliver drug molecules that has gone off-patent may seem more appealing to the pharmaceutical industry. In this regard, nanoparticle-based delivery technologies are emerging as attractive approaches to circumvent the limitations of conventional formulations administrated via oral, injectable or inhalable routes $[6,11,12]$. Encapsulating antimicrobial agents into nanoparticles intended for inhalation offers (i) protection of the antimicrobial agents from deactivation caused by the harsh local microenvironment in lungs with chronic bacterial infections (e.g., $\mathrm{pH}$ value, enzymes); (ii) decreased risk of adverse effects by reducing the drug exposure to the rest of body; (iii) controlled and potentially sustained drug release (i.e., prolonged residence time in lungs, which ultimately will impact patient compliance. Further, tailored properties of the nanoparticles may aid in (iv) overcoming the variety of barriers and resistance mechanisms by increasing drug uptake into and decrease efflux out of the bacterial cell; and (v) combinatorial delivery of multiple antimicrobial agents within the same nanoparticle, which may prompt bactericidal effects and prevent the development of antimicrobial resistance in bacteria (Fig. 1).

This review summarizes emerging efforts towards combating bacterial infections in the respiratory tract by using nanoparticle-based pulmonary delivery strategies, mainly focusing on lipid- and polymer-based nanoparticles owing to their good biocompatibility and translational perspective. The emphasis is on the design of nanoparticles with tailored properties to overcome the diverse biological barriers present in the pathological condition and accomplish site-specific delivery and release of payloads at the target site. In addition, current challenges for the translation from exploratory laboratory research to clinical application are discussed and potential solutions proposed.
Fig. 1 Illustration of structure of the most intensively investigated nanoparticles intended for inhalation and the potential mechanisms for improving therapeutic efficacy

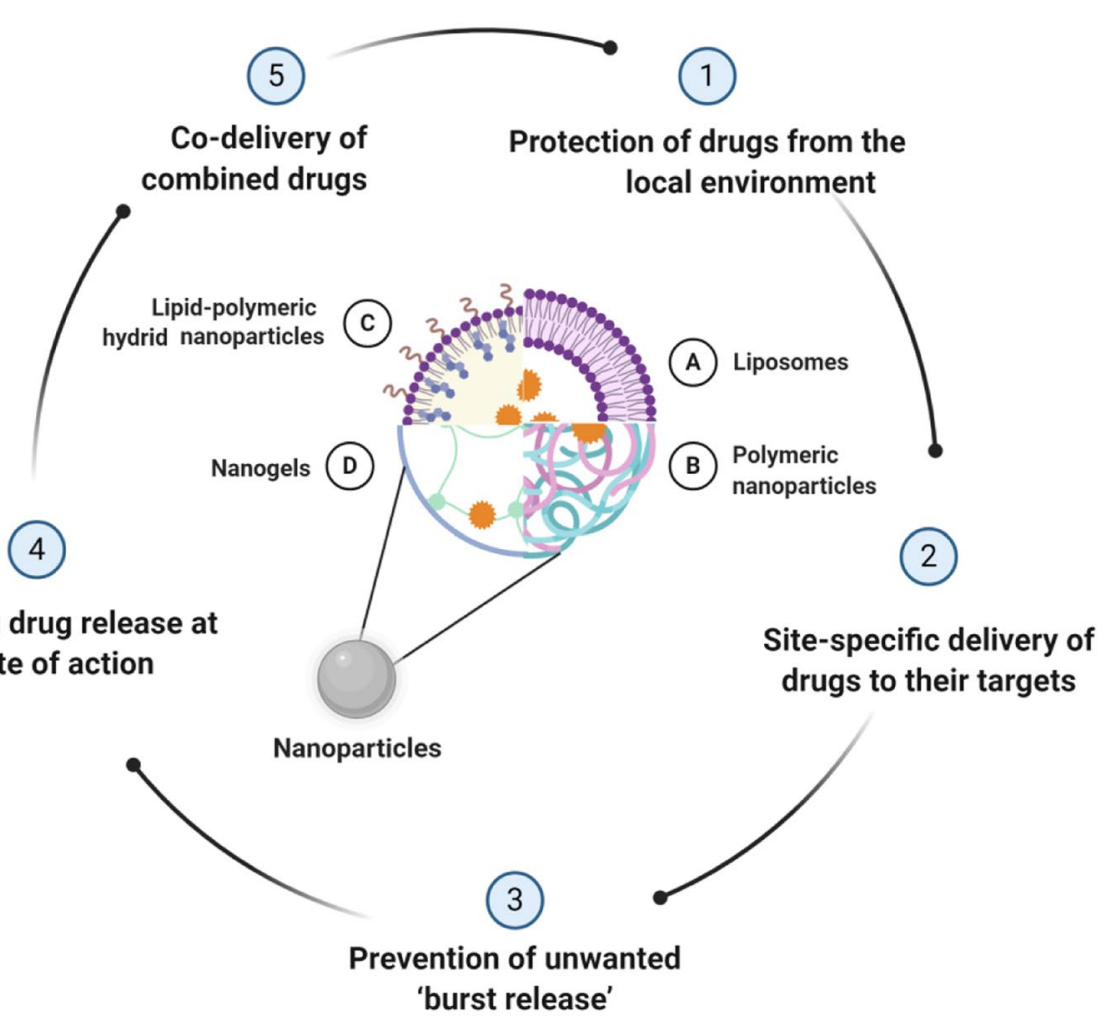




\section{Bacterial infection-related pulmonary diseases}

Lower respiratory tract infections describe a group of pathogen infections resulting in different epidemiologies, pathogeneses, and clinical presentations. Development of effective nanoparticle-based pulmonary drug delivery strategies to combat respiratory tract infections necessitates delicate consideration of the type of pathogens, the affected area within the respiratory tract, the pathophysiological progression and local microenvironment that the disease associates with. Examples of relevant diseases are illustrated in Fig. 2 and introduced in the following section.

\section{Chronic and recalcitrant infections in CF}

Cystic fibrosis is a severe life-shortening hereditary disease among Caucasians [13]. It is caused by mutations in a $230 \mathrm{~kb}$ gene on chromosome 7 encoding a 1480 amino acid polypeptide, which leads to impaired transport of chloride ions and abnormally viscous mucosal secretions [13]. The dysfunction of mucociliary clearance promotes bacterial colonization in the respiratory tract [14], consequently facilitating the formation of recalcitrant and highly resilient biofilms in cystic fibrosis (CF) mucus. Staphylococcus aureus and Haemophilus influenza are the most abundant bacterial species found in the early stage of the disease, whereas Pseudomonas aeruginosa, Burkholderia cenocepacia,
Stenotrophomonas maltophilia, and Achromobacter xylosoxidans are frequently found with the progression of disease [5]. Among these, the P. aeruginosa infections are responsible for most of the premature deaths of CF patients. Thus, preventing or postponing chronic pulmonary colonization by $P$. aeruginosa is among the primary aims in early CF treatment [15]. Inhaled antibiotics, combined with further oral or intravenous antibiotics, are considered a cornerstone of prevention and control of $P$. aeruginosa infections. The Food and Drug Administration (FDA) has approved inhaled tobramycin, aztreonam, and azithromycin for this indication, while the European Medicines Agency (EMA) has additionally approved the use of inhaled colistimethate sodium.

\section{COPD}

Chronic obstructive pulmonary disease (COPD) is the third leading cause of death [16], resulting in more than 3 million deaths worldwide and global prevalence of about 174 million cases in 2015 [17, 18]. COPD is characterized by complex chronic inflammation of the peripheral respiratory ducts and by an impaired innate defense of the lung parenchyma, resulting in progressive loss of normal pulmonary function. Bacterial infections caused by $H$. influenzae, Moraxella catarrhalis, Streptococcus pneumoniae and $P$. aeruginosa are clearly associated with the acute exacerbations of COPD [19, 20], constituting the main cause of mortality among COPD patients [21]. A small proportion of $P$. aeruginosa strains in the COPD patients acquire a mucoid
Fig. 2 Bacterial infectionrelated pulmonary diseases: (1) tuberculosis is an infectious disease caused by the bacillus Mycobacterium tuberculosis, which is well known to persist in macrophages within a granuloma formed in the infected lungs; (2) intracellular bacteria, such as Mycoplasma pneumoniae and Chlamydia pneumoniae, play important roles in acute pneumonia and bronchitis; and (3) recalcitrant bacterial infections may also occur as a co-morbidity of chronic pulmonary diseases, such as $\mathrm{CF}$ and COPD

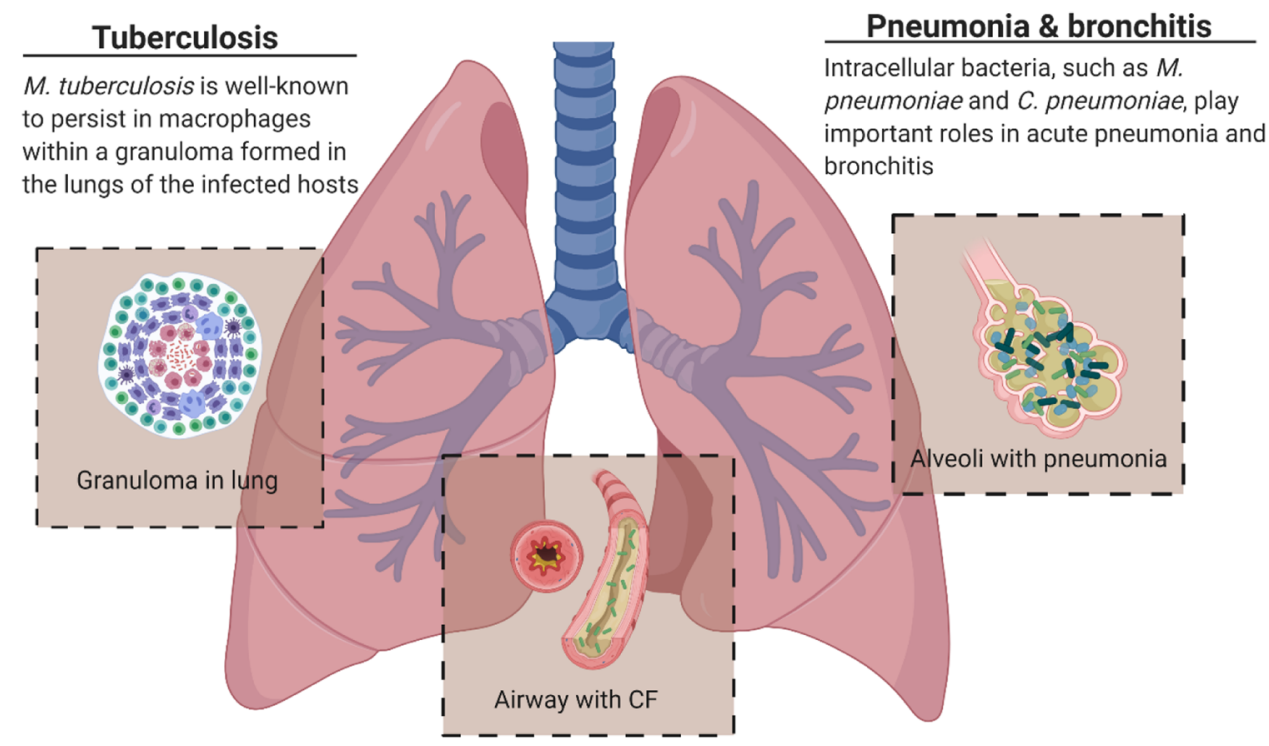

Chronic pulmonary diseases

Recalcitrant bacterial infections (e.g. P. aeruginosa) as a comorbidity of chronic pulmonary diseases, such as CF and COPD 
phenotype and establish the recalcitrant biofilms resembling those observed in CF [21, 22]. Thus, the experience learnt from treating CF patients might also be useful for developing new approaches for the prevention and treatment of $P$. aeruginosa infections in COPD. To date, antibiotic treatment is only used as short-term interventions for moderate and severe exacerbations due to concerns of antibiotic resistance development [23].

\section{TB}

Tuberculosis (TB) is caused by the bacillus Mycobacterium tuberculosis and remains an important infectious disease significantly affecting public health worldwide. According to the World Health Organization (WHO) report, in 2018, an estimated 10 million people contracted TB worldwide and 1.5 million people died from TB [24]. The emergence of multidrug-resistant bacillus strains, referred to as multidrugresistant TB and extensively drug-resistant $\mathrm{TB}$, further contributes to an emerging public health crisis [25]. The drugs used for first-line treatment of TB include rifampicin, isoniazid, pyrazinamide, ethambutol, and streptomycin. According to current treatment guidelines, long-term oral administration of anti-TB drugs with complex multidrug regimens and optimal medication adherence are required for standardized therapies of both drug-susceptible TB and drug-resistant TB [26]. The treatments result in poor patient compliance and often lead to life-threatening side effects. More importantly, M. tuberculosis is well known to persist in macrophages within granuloma formed in the lungs of the infected hosts [27]. The conventional therapy via systemic administration of anti-TB drugs often fail due to inefficient penetration of the drug into the alveolar macrophages [28, 29].

\section{Other diseases}

Non-CF bronchiectasis-related infections refers to a broad set of conditions that give rise to respiratory tract injury that results in inflammation, increased mucus secretions and infections that produce permanent airway dilatation [30]. Pathogens such as Veilonella sp., Prevotella sp., and Neisseria sp. have been identified in non-CF bronchiectasis-related infections [31, 32]. Ventilator-associated pneumonia (VAP) is a hospital acquired pneumonia that occurs $48 \mathrm{~h}$ or more after tracheal intubation. Early onset of VAP (i.e., occurring within 4 days of intubation and mechanical ventilation) is generally caused by antibiotic sensitive bacteria, such as $S$. pneumoniae, and methicillin-sensitive S. aureus. However, later infections are more commonly caused by multidrugresistant pathogens, including $P$. aeruginosa, Acinetobacter spp., and methicillin-resistant $S$. aureus. It is noteworthy that biofilms (e.g., of $P$. aeruginosa) will gradually form on the inner surface of the endotracheal tube and ventilator cycling can propel the biofilms and secretions to the distal airways, leading to persistent bacterial infections [33]. The atypical pneumococci, such as M. pneumoniae and Chlamydophila pneumoniae, $S$. aureus and certain Gram-negative rods are the usual pathogens encountered for community-acquired pneumonia [34]. Protracted bacterial bronchitis has also been reported as that most commonly caused by bacteria including S. pneumoniae and M. catarrhalis [35]. Aerosolized antimicrobial therapy has also shown great promises for the treatment of these pulmonary bacterial infections.

\section{Biological barriers to effectively targeted delivery of antimicrobials}

A variety of biological barriers impacts the delivery of drugs to the target site (Fig. 3). The properties of the barriers may vary depending on normal or pathophysiological conditions in the respiratory tract. Awareness of these biological barriers and the obstacles that they pose is key to improved drug delivery and thus therapy.

\section{Lung lining fluid}

Lung lining fluid is distributed continuously throughout the respiratory tract and is heterogeneous regarding its molecular composition and thus properties depending on whether the localization is the conducting parts (trachea, bronchi, and bronchioles) or the alveoli. The conducting parts are lined with a mucus gel-aqueous solution complex that functionally interacts with epithelial cilia as the mucociliary escalator. The alveoli are lined with alveolar subphase fluid and pulmonary surfactant [36].

Mucus is a complex mixture of water, mucins, globular proteins, salts, DNA, lipids, cells, and cellular debris [37]. It constitutes a natural protective layer on the surface of the epithelium located in the proximal part of the respiratory tract, e.g., the trachea, bronchi, and bronchioles. Its main functions include lubrication of the epithelia, maintenance of a hydrated layer on the epithelial surface allowing exchange of gases and nutrients with the underlying epithelium, as well as acting as a barrier to entry of pathogens and foreign substances [38]. Inhaled pathogens and foreign substances can be captured by the mucus via steric and adhesive trapping potentially followed by clearance via ciliary movement [39]. In healthy individuals, the thickness of the mucus layer ranges from 5-10 $\mu \mathrm{m}$ in the central lung with mesh sizes from 20 to $800 \mathrm{~nm}$, with the majority of the pores being less than $100 \mathrm{~nm}$ [40]. Mucins (high molecular weight glycoproteins of $200 \mathrm{kDa}-200 \mathrm{MDa}$ ) are the primary responsible constituents providing the inherent viscoelasticity of the mucus. However, respiratory tract diseases may induce pathological changes in the local microenvironment (e.g., altered 


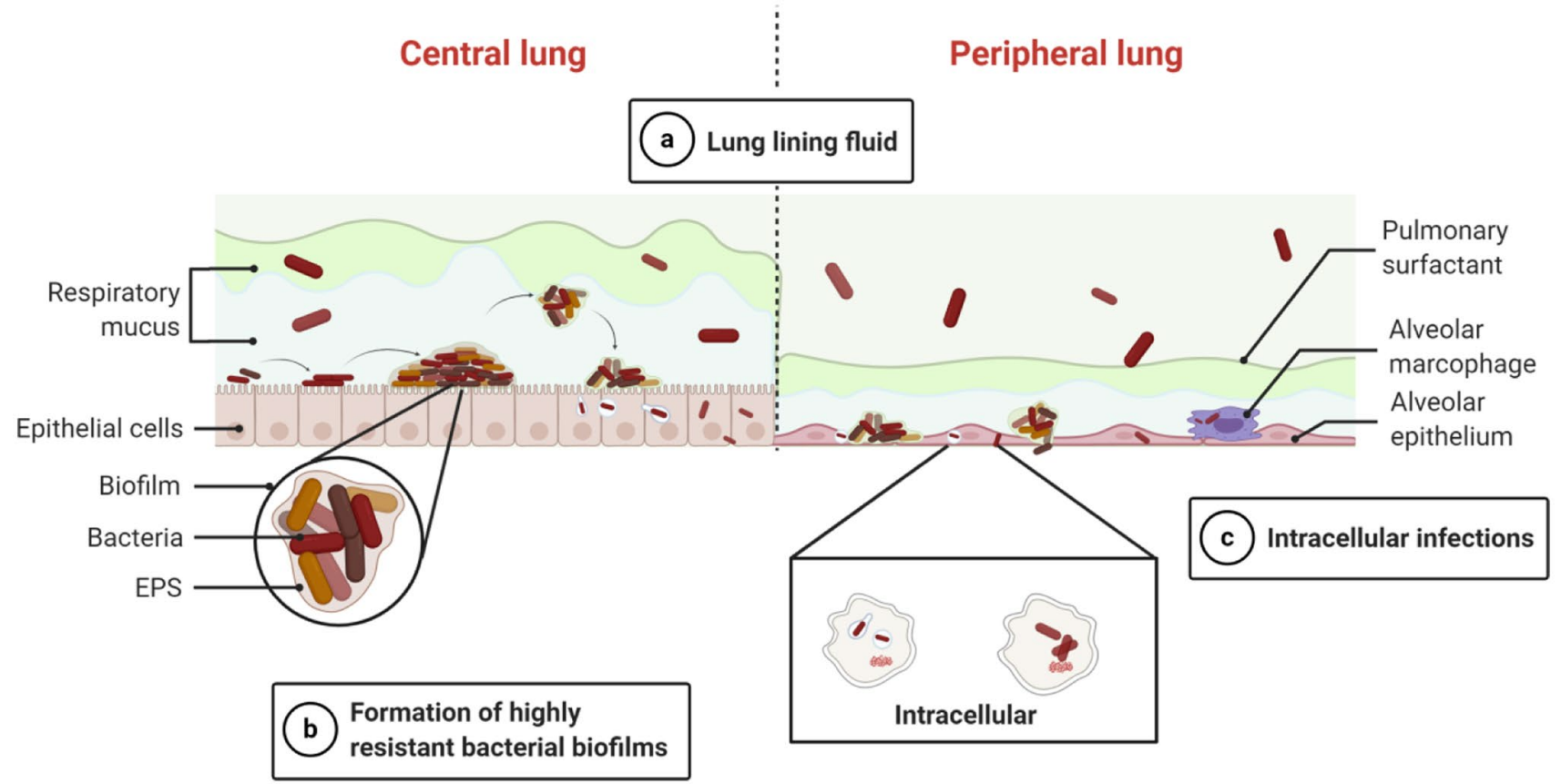

Fig. 3 Illustration of the challenges for effective aerosol antimicrobials delivery. a Lung lining fluid. b Formation of highly resistant bacterial biofilms. c Intracellular infections

$\mathrm{pH}$ value and ionic strength). For example, the $\mathrm{pH}$ value of lung lining fluid in the proximal part (on the surface of the mucus matrix) as well as the distal part of the respiratory tract under normal conditions is close to neutral. However, it will decrease to $\mathrm{pH}$ 6.0-6.5 under pathological conditions in, e.g., $\mathrm{CF}$ and COPD patients due to the chronic bacterial infections [41-43], which consequently significantly influence the conformational structure of the mucin molecules [44-46], and thereby affects the mucus-nanoparticle interaction [47]. In addition, the respiratory tract diseases induce overproduction and dehydration of mucus with important impact on the interaction between mucus and the drug molecule or the drug delivery system administered to the lungs [38]. Therefore, these pathological changes need to be carefully considered for rational design of inhalable nanoparticle delivery systems. Additionally, the adherent highly viscous mucus in the case of some pathological conditions may form embolisms in the trachea, bronchi, and bronchioles. This will further lead to obstruction of the respiratory tracts and changes in the bifurcation angles, which may affect the deposition of inhaled particles [48].

Pulmonary surfactant is an essential lipid-protein complex that generates a liquid surface layer at the air-liquid interface of the lung epithelium and it consists of a monolayer of surfactants and a surface-associated surfactant reservoir [49]. In addition to the physical stabilization of the alveoli during breathing, pulmonary surfactant also plays important roles in the innate immune defense. Recent studies have shown that pulmonary surfactants are present in all parts of the respiratory tract, but the composition of pulmonary surfactants in the central part of the respiratory tract is different from that in the alveoli [50]. The interaction of inhaled nanoparticles with pulmonary surfactant may negatively influence the biophysical function of the pulmonary surfactant, eventually resulting in nanotoxicity. In relation to this, formation of a surfactant lipoprotein corona on the surface of the nanoparticles may affect the fate of the inhaled nanoparticles and their efficacy. In addition, various lung diseases are associated with abnormalities in the composition and properties of the pulmonary surfactant [51]. Thus, to rationally design inhalable nanoparticles, it is necessary to understand the interaction of inhaled nanoparticles with pulmonary surfactant under pathological conditions [52].

\section{Bacterial biofilms}

A bacterial biofilm is a well-organized microbial community enmeshed in a polymeric, carbohydrate-rich extracellular matrix that can adhere to an inanimate or living surface [53]. The matrix components can be exopolysaccharides, proteins, nucleic acids, or other substances (referred to as extracellular polymeric substances, EPS) [54]. It is reported that over $60 \%$ of bacterial infections in humans worldwide involve biofilm formation, leading to numerous treatment failures in the clinic [55]. P. aeruginosa biofilm and Streptococcus pyogenes biofilm are often observed in CF-related infections 
and upper respiratory tract infections, respectively. Biofilm formation represents a protective microenvironment that allows bacteria to change growth rates and survive in hostile environments. It is reported that biofilm-forming bacteria can be 100-1000 times more resistant to antibiotics than planktonic bacteria [56]. Three mechanisms have been proposed to explain the general resistance of biofilms to bactericidal agents. The first is the physical barrier of the EPS matrix [54], which presents a cohesive, three-dimensional polymeric network that can transiently immobilize antimicrobial agents. This matrix may also act as an external digestive system, enabling the deactivation of antimicrobials if not sufficiently protected in a drug delivery system. The second mechanism is the existence of subpopulations of resistant phenotypes in the biofilm. Microbes are capable of acquiring resistance through various mechanisms including prevention of drug entry, expulsion of drugs via active efflux, mutation of targets, and enzymatic inactivation of the drugs [57]. The third protective mechanism involves the physiological state of the bacteria within a biofilm. The creation of starved, stationary phase dormant zones in biofilms seems to be a significant factor in the development of resistance of biofilm to antimicrobial agents because many antibiotics require some degree of cellular activity to be effective (i.e., the bactericidal mechanism of many antibiotics involves disruption of a microbial growth process). Thus, complete eradication of bacterial biofilm using current antimicrobial therapy based on single bacterial cell killing/ inhibition remains a great challenge due to the complex and multiple resistance mechanisms [53, 55, 58]. In general and as for other antimicrobial therapies, even though the majority of bacteria in a biofilm may be killed, a minority resistant fraction may quickly grow to become the dominant proportion of the population, eventually leading to the spreading of antimicrobial resistance.

\section{Intracellular infections}

Certain species of bacteria can invade and survive in various host cells in active or latent forms over prolonged periods of time, from which these bacteria can continue to induce a secondary site of infection, which results in persistent or recurrent infections [59]. For example, M. tuberculosis phagocytosed by alveolar macrophages can evade the killing processes in macrophages via establishing a survival niche within macrophages and/or escaping into the cytosol [60, 61]. Furthermore, recent epidemiologic studies have demonstrated the important role of intracellular bacteria, particularly $M$. pneumoniae and $C$. pneumoniae, in acute pneumonia and bronchitis, as well as in chronic respiratory diseases like asthma, CF, and COPD [62]. The majority of intracellular pathogen infects the mononuclear phagocytes system (MPS); however, a large variety of intracellular bacteria can also locate in nonphagocytic cells such as fibroblasts, hepatocytes, enterocytes, and epithelial cells [63]. Additionally, some typical extracellular bacteria, such as $S$. aureus [64] and $P$. aeruginosa $[65,66]$, have the ability to invade and localize inside host cells. Invasion of bacteria into host cells provides their protection from both the antimicrobial agents and the host immune system [10]. Thus, the treatment of intracellular infections remains a major challenge due to the poor intracellular penetration and short lung residence time of the commonly used antimicrobials. Therefore, in addition to the non-cellular barriers (e.g., respiratory tract mucus), nanoparticle delivery systems have to overcome the cellular and intracellular barriers, including host cell membrane, efflux pumps, exocytosis and endosomal degradation, to improve the penetration into and retention of antimicrobials inside host cells [63]. Furthermore, intracellular bacteria may localize in a harsh environment (e.g., the acidified phagosomes [67]) and the potential impact of the environment on antimicrobial agents and nanoparticle delivery systems must also be considered [68]. It is also noteworthy that intracellular bacteria may transform to non-replicating or to slowly replicating states, which can reduce their susceptibility to antimicrobial agents $[69,70]$.

\section{Advances in design of nanoparticle delivery systems}

Benefitting from the progress in the field of materials and nanotechnology, a variety of innovative nanoparticle systems with controllable properties have been developed for drug delivery purposes. In this section, we summarize the newest insights into tailored design of nanoparticles with optimal features to overcome the noncellular and cellular barriers in infected lungs to accomplish site-specific drug delivery.

The interactions of nanoparticles with the diverse biological barriers strongly depend on the physicochemical characteristics of the nanoparticles, such as their size [71-73], shape $[74,75]$, surface charge $[73,76]$, and surface hydrophobicity $[77,78]$. For example, nanoparticle with sizes less than $100 \mathrm{~nm}$ showed superior ability to overcome the steric barrier of mucus and EPS, allowing for adequate mucus and biofilm penetration $[79,80]$. Both electrostatic and hydrophobic interactions between nanoparticles and the components of noncellular barriers provide adhesion that impedes the nanoparticles' diffusion through the mucus and the EPS. The carboxyl and sulfate groups of the oligosaccharide chains provide mucin with a net negative charge and the non-glycosylated regions of the mucin mainly contribute to the hydrophobicity [50]. Thus, in general, nanoparticles with a sufficiently hydrophilic and net-neutrally charged surface can effectively minimize the adhesive interactions between mucin and nanoparticles. PEGylated nanoparticles and 
virus-like nanoparticles have shown good mucus penetration [81, 82] and biofilm-interacting properties [83]. In addition, the surface properties (e.g., charge and hydrophobicity) are also important determinants for in vivo respiratory toxicity. It was found that nanoparticles with a negatively charged surface showed reduced local inflammation compared to their cationic counterparts [84]. In addition, nanoparticles with hydrophobic surfaces tend to induce acute respiratory toxicity upon single-dose administration [85].

As for intracellular infections, nanoparticles can be engineered to passively and actively target infected cells and enhance the accumulation in infected cells. Various ligands, including mannose, maleylated bovine serum albumin, and O-steroyl amylopectin, have been used to modify the surface of nanoparticles and enhance the uptake of nanoparticles by infected macrophages $[63,86]$. However, it remains unclear if the surface decorations can conserve their targeting activity during and after penetrating through the lung lining fluid. Another key challenge in combating intracellular infections is to precisely deliver antibiotics to the subcellular compartments where the target bacteria are located. Thus, information on intracellular trafficking of both bacteria and nanoparticles is of importance for designing nanoparticles with optimal properties. In general, nanoparticles that can penetrate cells through nonendosomal internalization pathways or rapidly escape from endosomes are superior in reaching bacteria residing in the cytoplasm, and avoid the possible deactivation of antibiotics in the endo-lysosomal pathway. As reported, rapid escape from endosome can be achieved by modifying the nanoparticles with cell-penetrating peptides, fusogenic lipids, or listeriolysin-O [87].

Examples of lipid and polymer-based nanoparticles developed for treatment of biofilm and intracellular pulmonary infections in the last 5 years are presented in Table 1. In addition, advantages and disadvantages of lipid and polymer-based nanoparticles for treatment of biofilm and intracellular pulmonary infections are summarized in Table 2.

\section{Liposomes}

Liposomes are spherical vesicles composed of one or more phospholipid bilayers, in which the hydrophilic heads orient toward the aqueous medium and the hydrophobic tails constitute the inner region of the membrane. A significant advantage of using liposomal formulations is that, when tailored to contain fusogenic lipid bilayers, they have the unique ability to fuse with the membranes of bacteria, thereby allowing for increased drug retention and intracellular delivery of encapsulated therapeutics [107]. Furthermore, owing to the surfactant properties of phospholipids, liposomes are also capable of penetrating through the mucus layer, thereby attaining access and close proximity to bacteria [108]. In a recent study, amikacin encapsulated in liposomes also showed effective penetration into biofilms [109] and enhanced cellular uptake in macrophages compared to nonformulated amikacin [110]. In addition, PEGylation of the liposomes can effectively reduce nonspecific interactions, thereby improving the mucus and EPS penetration. However, the PEGylation may also reduce their interactions with bacteria, leading to unwanted effects, such as short residence time in bacterial biofilm. Recently, reversible PEGylation of liposomes containing a pH-cleavable PEG pyridylhydrazone derivative (e.g., coupling bifunctional PEG via pyridylhydrazone linkage to cholesterol) has been successfully been used for tumor-specific drug and gene delivery $[111,112]$. However, it is debatable if the $\mathrm{pH}-$ stimulated reversible PEGylation of liposomes is optimal for a combination of mucus-penetrating properties with targeted drug delivery to bacteria and infected cells. The reason is that the acidic $\mathrm{pH}$ level in lung lining fluid in lungs with chronic bacterial infections may result in that the liposomes switch their surface charge prior to reaching to the bacteria and cells.

The liposomal composition seems to be a critical factor influencing not only encapsulation and release of the antimicrobials, but also mucus and biofilm penetration, fusogenicity, and overall intracellular delivery. Although adequate efforts have been made to address the effect of the liposomal composition on these properties individually, little knowledge is available on the interplay among them, which is indeed very vital for optimizing the liposomal composition. For example, it is well known that the liposomes made of phosphoethanolamine (PE) moieties usually possess good fluidity, but it is not clear if PE-based liposomes possess optimized mucus- and biofilm-penetrating properties. On the other hand, to ensure optimal fusogenicity, the fluidity of liposomes needs to be tuned according to the properties of the bacterial outer membrane by incorporating phospholipids with different properties in the liposomes. However, this may also influence the drug encapsulation. Therefore, the optimal liposomal compositions need to be sophisticatedly selected and investigated according to the encapsulated antimicrobials and the properties of the targeted bacteria [113]. In addition, the choice of lipid composition may further offer targeting to biofilms. To date, phosphatidylinositol (PI), stearylamine (SA), dimethyldioctadecylammonium bromide (DDAB) and 3 $\beta-(\mathrm{N}(\mathrm{N} 1 \mathrm{~N} 1-$ dimethylaminoethane) carbamoyl) cholesterol (DC-chol) have been incorporated into liposomes to increase their targeting to biofilms through non-specific interactions (charge-based and hydrogen bond interactions between components in the liposomes and the biofilms) [114-117]. The easy-to-modify surfaces of liposomes also enable incorporation of specific targeting ligands that selectively bind to a target molecule inside the biofilm and/ or the infected cells such as antibodies [118], lectins (concanavalin A and wheat germ agglutinin) [119, 120], and mannose [121]. In spite of promising results obtained from reported 


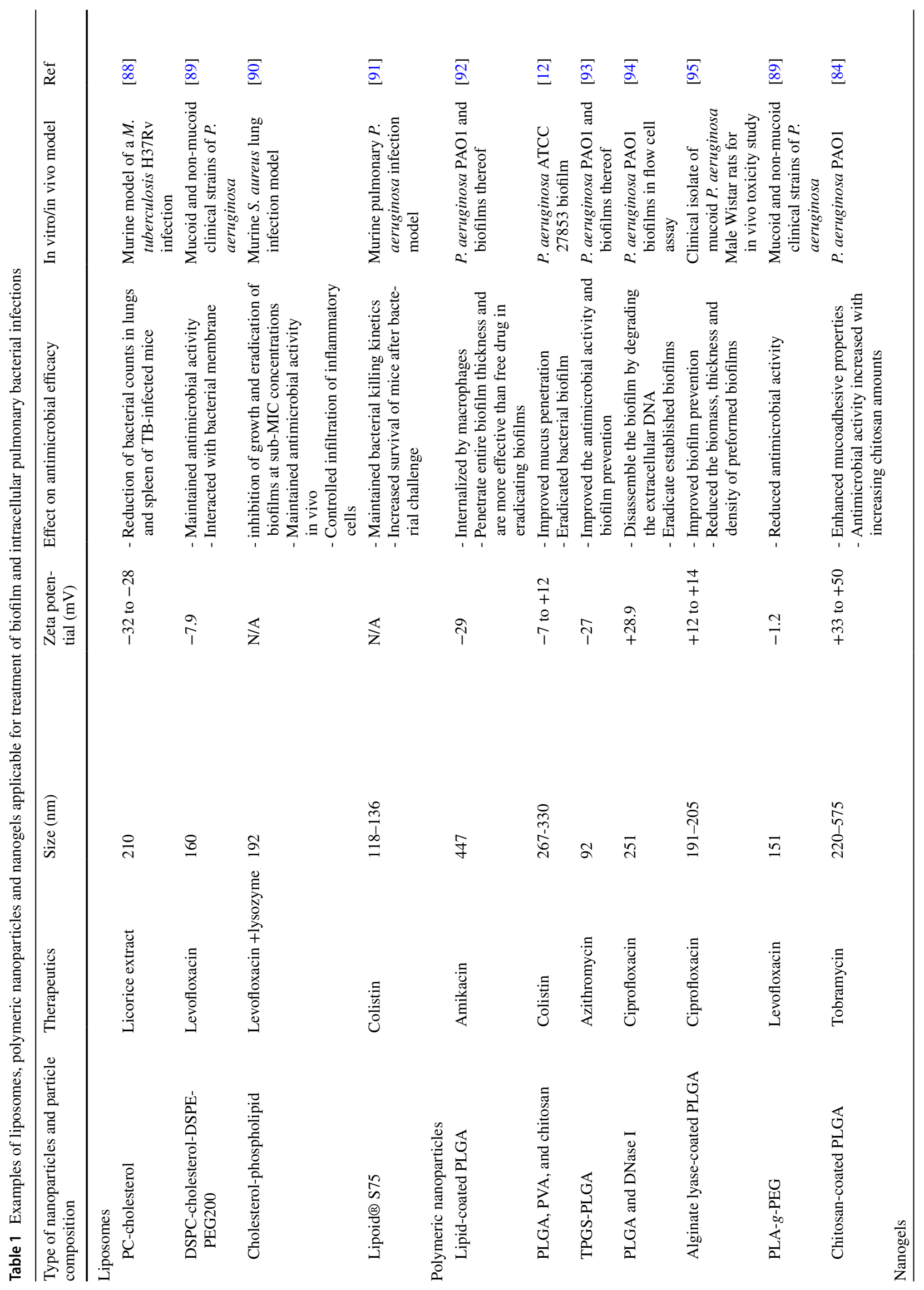




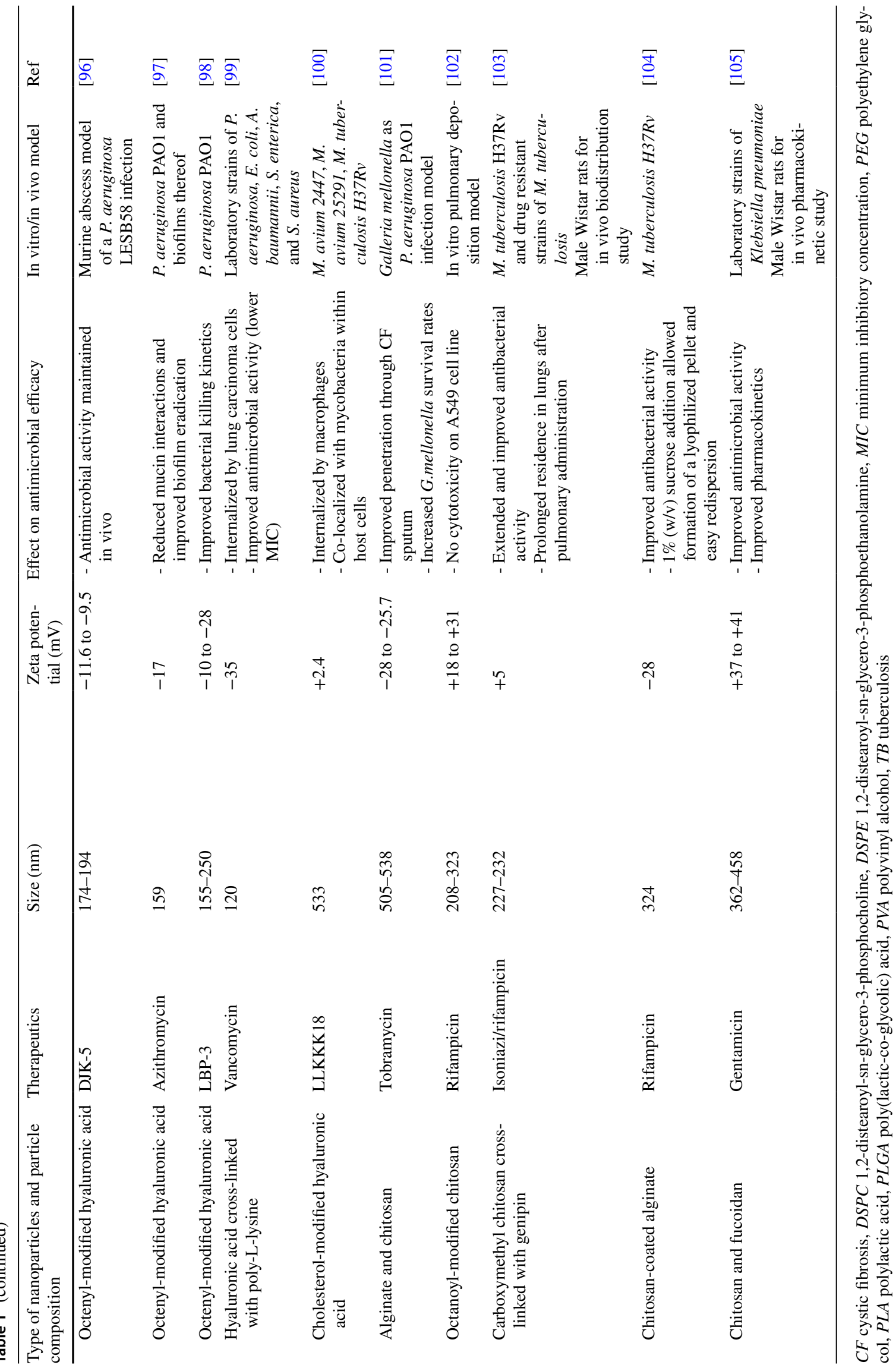




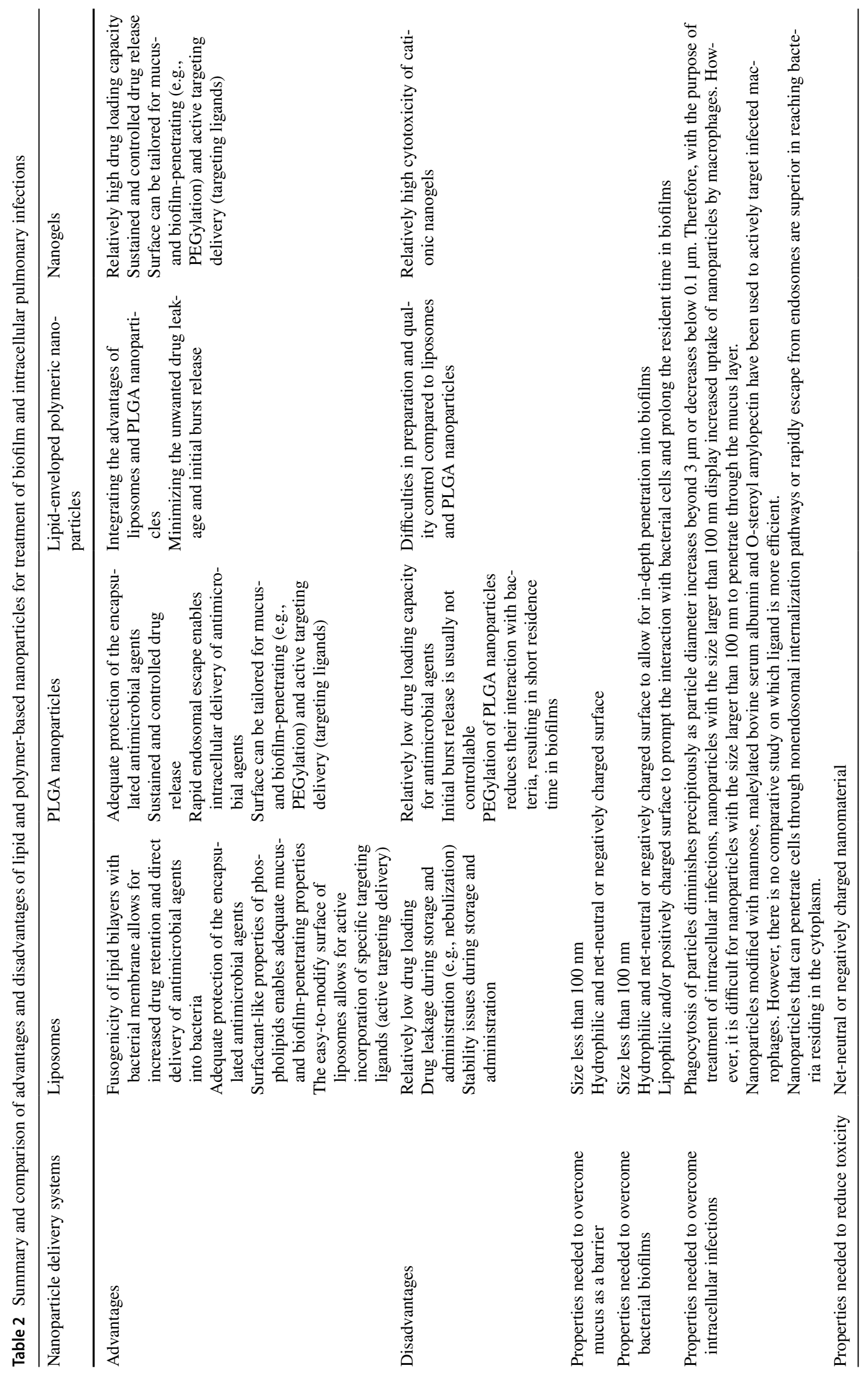


proof-of-concept studies, the targeting efficacy in a pathological microenvironment in lungs is still unconfirmed. It is noteworthy that lipid shells composed of fusogenic lipids can promote rapid escape of nanoparticles from endosomes [87]. Liposomal resorcinomycin A and liposomal clofazimine showed significant enhancement of antibacterial activity against intra-macrophagic Mycobacterium avium-mycobacterium intracellulare complex (MAC) infections over the free corresponding drugs in vitro.

At present, Arikayce ${ }^{\circledR}$ (liposomal amikacin for inhalation, or LAI, also known as Arikace ${ }^{\circledR}$ ) has been approved for treatment of lung infections caused by $M$. avium complex (MAC), a type of non-tuberculous mycobacteria (NTM), in adult patients with $\mathrm{CF}$ as well as for other lung diseases where the patients have not responded to traditional therapies. In addition, Apulmiq ${ }^{\circledR}$ (liposomal ciprofloxacin for inhalation, previously known as Linhaliq ${ }^{\circledR}$ and Pulmaquin ${ }^{\circledR}$ ) is in a confirmatory phase 3 trial recommended by the FDA. However, the inherent drawbacks associated with liposomes (e.g., chemical and physical instability, drug leakage during storage, and premature drug release) limits further development. In contrast, polymeric nanoparticles may represent promising alternatives.

\section{PLGA-based nanoparticles}

Poly(lactic-co-glycolic acid) (PLGA) is an FDA-approved copolymer for therapeutic use in humans in various drug delivery systems owing to its high biocompatibility and safety [122]. Therapeutic compounds can be encapsulated into a PLGA nanoparticle matrix to achieve slow and sustained release at the target site. This may not only prolong the contact time between antimicrobials and bacterial cells, eventually increasing antimicrobial efficacy, but also provide a steady drug pharmacokinetic/pharmacodynamic profile for prolonged periods and thus may represent a promising approach to prevent the emergence of antimicrobials resistance. The drug release from a PLGA matrix can be tailored by varying the monomer composition (lactide/glycolide ratio), molecular weight and chemical structure (i.e., capped and uncapped end-groups). In addition, aerosol administration of PLGA-based delivery systems has shown no toxicity to both healthy [123-125] and CF-affected human respiratory tract epithelial cells $[126,127]$.

PLGA nanoparticles can be effective carriers for intracellular delivery of antibiotics, and intracellular trafficking studies showed that PLGA nanoparticles can efficiently concentrate in the inclusions within which Chlamydiae reside in the host cell cytoplasm. In addition, PLGA nanoparticles modified with tuftsin (a natural immunostimulatory tetrapeptide with macrophage-targeting and stimulating ability) derivatives presented increased the internalization rate and intracellular activity of the encapsulated drug candidate against M. tuberculosis in vitro [128]. However, due to the hydrophobic nature of this copolymer, the interactions of PLGA nanoparticles with mucin and EPS seem to hinder their diffusion in mucus and bacterial biofilms. As with liposomes, the hydrophilic PEG polymer has been used for surface modification of PLGA nanoparticles to reduce nonspecific interactions [50,129]. PEGylation has been demonstrated to significantly improve the movement of nanoparticles in sputum $[130,131]$ and human lung mucus [132]. The improvement in the mobility of nanoparticles highly depends on the molecular weight and the density of PEG on the particle surface [133]. For example, the penetration of $200 \mathrm{~nm}$ nanoparticles through CF sputum was more feasible when they were coated with PEG with molecular weights between 2 and $5 \mathrm{kDa}$ [79], whereas nanoparticles coated with $10 \mathrm{kDa}$ PEG displayed mucoadhesion [132, 134]. PEGylated nanoparticles also showed a higher degree of free movement in biofilm compared to lipophilic particles and drug molecules $[135,136]$. In addition, the potential of PEGylated nanoparticles for transport of antimicrobial agents in biofilms of Burkholderia multivorans, Burkolderia cepacia, and P. aeruginosa has also been observed [135, 137]. Hindered mobility of both anionic and cationic nanoparticles in the size range of 100-200 nm was observed in bacterial biofilms and CF sputum, while their PEGylated neutral counterparts showed increased mobility both in sputum and in $P$. aeruginosa biofilm. Interestingly, PEGylation increased the mobility of the particles in biofilms more than in CF sputum. However, there is also a concern that PEGylation could potentially facilitate the escape of PEGylated nanoparticles from the biofilm with the hydrodynamic flow and thus PEGylation could represent a drawback to the longterm sustained delivery of antimicrobials in the biofilms. To address this issue, an environment adaptive polymer, $\mathrm{D}-\alpha$ tocopheryl polyethylene glycol 1000 succinate (TPGS), has been applied for surface functionalization of PLGA nanoparticles [93, 97]. TPGS is an FDA-approved pharmaceutical excipient consisting of a lipophilic moiety (vitamin E) and a hydrophilic moiety (PEG) $[138,139]$ and is documented to be cleaved into vitamin E and PEG by enzymes secreted by bacteria [140-142]. Our recent study showed that the mucus-inert, enzymatically cleavable TPGS shell can reduce non-specific interactions of the nanoparticles with pulmonary surfactant and mucin [47, 52], and allow accumulation of the nanoparticles deep in the biofilms [93].

In addition, $\mathrm{pH}$-sensitive, surface charge-switching nanoparticles made of PLGA, poly-L-histidine (PLH) and PEG have been developed and investigated to promote the targeting to bacteria through electrostatic interactions [143]. Owing to the PLH segments containing imidazole groups, the triblock polymer maintains a negative charge at normal physiological $\mathrm{pH}$ (7.4); however, it can switch the surface charge to positive when exposed to bacterial infection-related acidic pH levels (6.0-6.5). Thereby, the 
pH-sensitive, surface charge-switching property facilitates a strong multivalent electrostatic-mediated binding to negatively charged bacterial cell walls, thus, increasing the local accumulation of the bactericidal components and enhancing the antimicrobial efficacy. In addition to PLGA-PLH-PEG, the nanoparticles made of the diblock copolymers composed of 2-(dimethylamino)ethyl methacrylate (DMAEMA), butyl methacrylate (BMA), and 2-propylacrylic acid (PAA) and polymeric micelles with mixed-shell composed of PEG and $\mathrm{pH}$-responsive poly ( $\beta$-amino ester) (PAE) have also been investigated to promote local accumulation through electrostatic interactions $[144,145]$. In spite of the great promise demonstrated in in vitro cultured bacterial biofilms, the surface charge-adaptive approach based on $\mathrm{pH}$ sensitive polymers may be not applicable for aerosol antimicrobial delivery owing to the fact that the pathological microenvironment in lungs of the patients with chronic respiratory tract infections, such as the acidic pH level (approximately 5.5-6.5) and the elevated salt concentration of lung lining fluid, could lead to mistargeting of the nanoparticles.

\section{Lipid-enveloped polymeric nanoparticles}

Lipid-enveloped polymeric nanoparticles (LPNPs) are core-shell structures comprising polymeric cores and lipid shells. Owing to the integrated characteristics of both polymeric nanoparticles and liposomes, LPNPs have rapidly emerged as a robust drug delivery platform with versatile applications, such as vaccine adjuvants, cancer diagnostic and therapy, and gene delivery [146]. Recently, LPNPs have also been investigated as antimicrobial delivery vehicles for lung biofilm infection therapy. Cheow et al. compared the antibiofilm efficacy of levofloxacin-loaded PLGA nanoparticles and lipid-PLGA hybrid nanoparticles against $P$. aeruginosa biofilms [147]. It was found that lipid-PLGA hybrid nanoparticles presented twice higher loading capacity of levofloxacin than PLGA nanoparticles, which could be attributed to the fact that the lipid coating can reduce drug diffusion from the oil phase into the aqueous phase during the emulsification step in the preparation process. In addition, they also observed that the hybrid nanoparticles exhibit higher antibacterial efficacy against biofilm, possibly due to superior penetration into the biofilm matrix. However, it was observed that the phosphatidylcholine (PC)-based monolayer on the hybrid nanoparticles did not prompt the biofilm affinity. In contrast, a cationic lipid (i.e., 1,2-dioleoyl-3-trimethylammonium-propane, DOTAP) shell enabled the LPNPs to anchor onto surfaces of a diverse range of Gram-positive and Gram-negative bacterial pathogens [148]. However, the positive charge may impair the mucus-penetrating property, thus be inefficient in the treatment of respiratory tract infections. As an alternative, lipid bilayerenveloped polymeric nanoparticles demonstrated intensive interaction with bacterial biofilm and effective mucus penetration. Interestingly, the coexistence of both positively charged lipids
(DOTAP) and zwitterionic, PEGylated lipids in the lipid bilayer can further reduce the interaction of nanoparticles with mucin, but elevate the interaction with bacterial biofilm [83], possibly owing to the virus-like surface (i.e., hydrophilic with a high charge density, but net neutral due to the high concentration of both cationic and anionic groups) [81]. In theory, the lipid shell can potentially impede water penetration into the nanoparticle, thereby reducing the drug release rate, especially for the drugs with a low permeability through lipid membranes. Importantly, drug release from the LPNPs can be triggered by rhamnolipids, thereby providing higher concentration in close proximity of $P$. aeruginosa biofilms [149]. Recently, inspired by the natural pathogen-host interactions, cell membrane-coated nanoparticles have emerged as a versatile delivery platform that may be applied to treat numerous infectious diseases [150].

\section{Nanogels}

Nanogels have received increasing attention over the last years owing to their combined features of hydrogels and nanoparticles. Nanogels are made of cross-linked water-soluble natural or synthetic polymers that have the ability to absorb high amounts of water or biological fluids into the formed network while maintaining their structure [151, 152], owing to the presence of hydrophilic groups such as $-\mathrm{OH},-\mathrm{CONH}-$, $-\mathrm{CONH}_{2}-$, and $-\mathrm{SO}_{3} \mathrm{H}$ [153]. Nanogels can be synthesized via both physical and chemical cross-linking of polymers. Compared to chemically cross-linked nanogels, physically cross-linked nanogels is prepared under mild conditions, making them more favorable for biomedical applications. However, physically cross-linked nanogels present relatively poor mechanical stability in comparison with chemically cross-linked nanogels. Nanogel-based delivery systems allow for high loading of proteins, peptides and other biological compounds (such as oligonucleotides and DNA) through formation of salt bonds, hydrogen bonds, or hydrophobic interactions. Therefore, the loading capacity of nanogels is superior to that of most other nanocarriers [154]. The release of encapsulated cargos from nanogels occurs through swelling of the polymer matrix and drug diffusion out of the nanogels in a physiological environment [99]. Thus, polymer structure, degree of crosslinking and polymer ratios can be tailored to achieve the desired release behavior [151, 152]. In addition, drug release from nanogels can occur in response to a wide variety of environmental stimuli, such as ionic strength, $\mathrm{pH}$ and temperature $[154,155]$. It is also worthy to mention that the low interfacial tension and the deformability of nanogels can potentially minimize non-specific protein adsorption [151], and improve their penetrating properties across mucus and EPS, making nanogels superior nanocarriers for inhalation therapies. Gentamicin-loaded into chitosan/fucoidan nanogels administered intratracheally showed superior pharmacokinetics when compared to intravenously administered 
gentamicin [105]. Intratracheal administration of the nanogels reduced plasma levels of gentamicin and may thus reduce nephro- and ototoxicity known to be associated with gentamicin treatments. Genipin-crosslinked chitosan based nanogels have also been formulated into an inhalation powder for lung delivery [103]. Upon pulmonary administration to rats, the nanogels slowly released the encapsulated antimicrobials, resulting in longer drug residence time in the lungs and decreased the levels in other organs, which is expected to reduce side effects associated with the treatment. These findings confirm the significance of the targeting potential of such a delivery system. Additionally, chitosan-based nanogels were nebulized using a PariBoy air-jet nebulizer into a twin stage impinger [102] - a device used regularly for assessing drug delivery from metered dose inhalers and other inhalation delivery devices [156]. The results show that the fine particle fraction, which represents the proportion of product predicted to likely deposit in the lower airways to be $43 \%$. These findings indicate the suitability of nanogels for nebulization and administration to the lower respiratory tract.

Both cationic and anionic polymers have been utilized for preparation of nanogels. Chitosan is a cationic, non-toxic, linear polysaccharide biopolymer. Chitosan and its derivatives are found attractive for pulmonary delivery of antibacterial drugs because chitosan itself has shown antimicrobial activity against clinical isolates of $B$. cepacia complex [157] and Streptococcus mutans biofilms [158]. The mechanisms may include alteration of the cell membrane permeability, binding with the bacterial DNA, or chelation of trace metals that interferes with the production of virulence factors and bacterial growth [159]. The derivatives of chitosan such as carboxymethyl chitosan and octanoyl chitosan have been investigated to prepare nanogels for pulmonary delivery of anti-TB drugs. For instance, octanoyl chitosan improved the organic solubility of chitosan, thereby allowing for preparation of crosslinker-free nanoparticles using a double emulsion solvent evaporation technique for pulmonary delivery of rifampicin [102]. In general, chitosan-based nanogels have demonstrated increased residence and close contact with mucosa due to their mucoadhesive property [160]. However, the positive charge of chitosan allow for crosslinking with mucin, resulting in the formation of viscous mucus and impediment of mucin gel hydration [161]. Additionally, chitosan has also been shown to affect tight junctions and increase permeation of nanoparticles across epithelium, potentially leading to systemic drug exposure. Therefore, appropriate surface modification of chitosan-based nanocarriers intended for inhalation is highly needed. Surface coating with hydrophilic anionic polymers, such as alginate and hyaluronic acid, represents an effective approach to reduce the interaction of nanoparticles with mucus [162], possibly due to the combined effects of electrostatic repulsion, chelation, reduction in intra/inter-mucin hydrogen bonding density, and network hydration [161]. Hyaluronic acid (HA) is a natural, hydrophilic and anionic polymer of interest as it has shown the ability to reduce inflammation and improve tolerability of hypertonic saline inhalations in patients with CF $[163,164]$. HA can be modified with lipid side chains, which allow physical cross-linking of the polymer chains by self-assembly in water, leading to the formation of nanogels with good loading capability for various therapeutic agents. The lipid-modified HA-based nanogels have shown great promise in combating biofilm and intracellular infections. For example, octenyl-modified HA has been used to prepare nanogels, which showed good mucus and biofilm penetration [97]. Furthermore, octenyl-modified HA-based nanogel encapsulating a peptidomimetic showed improved antibacterial activity and safety profile [98]. In addition, encapsulation of DJK-5 (an antimicrobial peptide) into the octenyl-modified HA-based nanogel was observed to reduce peptide toxicity in vivo while maintaining the antimicrobial activity [96]. Nanogels formed with cholesterol-modified HA allowed intracellular delivery of the peptide LLKKK18, indicating applicability of nanogels for treatment of intracellular infections [100]. The cholesterol-modified HA nanogel has also been used for encapsulating hydrophobic compounds to improve their water solubility and allowed intracellular delivery into endothelial cells [165].

\section{General consideration on the translation from exploratory research to clinical application}

Through multiple efforts in the past decades, significant advances in overcoming biological barriers to achieving site-specific delivery of antimicrobials at sufficiently high concentrations have been obtained. In spite of promising data shown in proof-of-concept studies, several issues need to be addressed further to prompt the translation of research to clinical applications.

\section{Increasing loading capacity}

The drug loading capacity of nanoparticles and how much of the drug delivery system can be inhaled determines how high doses of the antimicrobials can be delivered to the site of action. Sufficient loading capacity may often be a limiting factor; thus, the type (liposome, solid PLGA-based, soft nanogel, etc.) and specific composition (choice and combination of specific lipids or polymers) of the nanoparticle should be tailored to the physicochemical properties of the drug molecule to be encapsulated. For reasons mentioned previously, the burst dose must be sufficient to significantly inhibit and preferably kill the target pathogen, and in some cases sustained release kinetic drug profiles after the initial 
burst dose may be advantageous. For sustained-release nanoparticles, sufficient drug loading is thus a prerequisite for not only reaching but also maintaining therapeutic concentrations of antimicrobials within a longer period of time, and if successful, this may naturally reduce the dosing frequency. In addition to ensuring a therapeutic effect, increasing loading capacities results in lower amounts of nanomaterials needed, which will minimize the overall possible risk of cytotoxicity and other adverse effects induced by the nanomaterials.

In more detail, the loading capacity of antimicrobials into both liposomes and polymeric nanoparticles are often less than $5 \%(\mathrm{w} / \mathrm{w})$, which is not sufficient for eliciting the desired effect. Several approaches have been investigated to increase the encapsulation efficiency and loading capacity of antimicrobials, such as incorporation of alginate into PLGA matrix, changing the $\mathrm{pH}$ at which the nanoparticles are formed, and complex drug with polyelectrolytes prior to encapsulation [113]. In our recent work, carbon quantum dots (CQDs) were incorporated into PLGA nanoparticles by using a microfluidic method with the aim to improve drug loading of azithromycin and tobramycin in the PLGA particles. Our results show that both physical sorption and intermolecular hydrogen bonding between CQDs and antibiotics contributed to the improved loading capacity (up to approximately $30 \%$, w/w), and decreased the premature burst release [166]. It is worth mentioning that the CQD-PLGA hybrid nanoparticles result in good photothermal effects, which allows for (i) stimuli-responsive release of the payloads by disrupting the nanoscale network of the nanoparticles [167, 168] and (ii) increasing the permeability of the bacterial membrane [169]. However, the biocompatibility of CQDs needs to be addressed prior to translation for pulmonary use.

\section{Optimizing the drug release kinetics}

One of the important advantages of nanoparticle-based drug delivery is that nanoparticles can provide sustained drug release, thereby potentially reducing the dosing frequency. However, rationally customizing drug release from nanoparticles requires an in-depth understanding of the residence time of nanoparticles. For example, mucoadhesive nanoparticles are generally captured in the luminal mucus layer and then largely removed from the respiratory tract by the mucociliary clearance. Thus, there is no benefit of drug release for longer than that of the residence time of the nanoparticles in the lung. In contrast, mucus-penetrating particles with the ability to diffuse through mucus can avoid rapid mucociliary clearance in vivo and remain in the lung longer, thus potentially maximizing the "effective drug exposure" to the lung. A recent work demonstrated that pulmonary delivery of fluticasone propionate formulated in mucus-penetrating nanoparticles achieved a higher local exposure in lungs of rodents compared to that achieved with both non-formulated drug and with a mucoadhesive formulation with similar particle size and in vitro drug release profile [106].

In addition, drug release kinetics constitutes an important factor for antimicrobial efficacy. In some cases, the encapsulated drugs tend to be quickly released, potentially during the nebulization process and/or prior to reaching to the site of action (i.e., premature leakage/release), which consequently may result in insufficient drug concentrations at the site of action. Thus, effective approaches to minimizing drug leakage prior to dosing and premature release are highly needed. However, controlling the release kinetics at the site of action is also crucial based on the mode of action of the given antimicrobials. It is known that most antibiotics can be divided into two categories based on their mode of action, namely, (i) time-dependent killing antibiotics (e.g., aminoglycosides, fluoroquinolones) and (ii) concentration-dependent killing antibiotics (e.g., beta-lactam antimicrobials). For the latter, the bacteria killing efficacy is elevated with increasing ratios of maximum drug concentration to minimum inhibitory concentration (MIC) $\left(\mathrm{C}_{\max } / \mathrm{MIC}\right)$ and/or of area under the curve (AUC) to MIC (AUC/MIC). In contrast, the bacteria killing efficacy of time-dependent killing antibiotics is positively correlated to the duration of time that drug concentration remain above the MIC (T > MIC) [170]. Therefore, in terms of sustained release formulations, the release kinetics should be optimized according to the therapeutically relevant pharmacodynamics of the given antimicrobials $[5,171]$. In the case of nanoparticles loaded with a combination of antimicrobials for synergistic effects, sequential release kinetics of the individual antimicrobial agent should also be considered to maximize the antimicrobial efficacy. As an example, stimuli-responsive delivery systems, which can respond to either endogenous or exogenous stimuli, represent a promising strategy to tailor the drug release with spatial and temporal dosage control $[172,173]$. However, rational design of stimuli-responsive nanoparticles for combating respiratory bacterial infections necessitates delicate considerations in relation to the complex lung microenvironment present in the case of respiratory tract infections.

To effectively and rationally optimize the drug release kinetics, standardized in vitro dissolution and release testing methods for inhalable formulations are highly necessary. A range of techniques including paddle-over-disk USP 2 dissolution apparatus, flow-through cell dissolution apparatus, and diffusion cell apparatus, have been developed to investigate the dissolution and release rates of inhaled products [174]. However, considering the unique features of the local microenvironment in lungs, such as the extremely small amount of fluid and the presence of endogenous lung surfactants and airway mucus [175, 176], these standard techniques may be suboptimal for testing inhalation formulations. Thus, significant efforts are highly needed on creating 
surrogates that more accurately resemble the local microenvironment of lungs taking the effect of chronic bacterial infections into account.

\section{Preclinical models used in studies of respiratory tract infectious diseases}

Innovative delivery systems must be proven as safe and effective before entering clinical trials. Preclinical models, including in vitro, ex vivo, and in vivo models, are applied to best possibly predict in vivo responses (e.g., safety and efficacy) in humans. To prompt successful translation of new therapeutic strategies to clinical trials, preclinical models should also provide insight into the interaction of a drug or a carrier with the delivery barriers present in the infected human lung (Fig. 3). So far, an impressive number of pulmonary models have been established. The choice of preclinical models highly depends on the research stage. For example, in vitro models, mimicking a part of the lung barrier and/or function, are usually employed to answer specific questions and optimize the design of the delivery systems. In spite of allowing investigations of interaction between formulations and cells or single organs in a precise and cost-effective manner, most of the in vitro models fail to reflect relevant (patho-)physiological features and the complex interplays within a living organism. Therefore, animal experiments represent the best possible modes to predict first human dose and outcomes of clinical trials. However, owing to the major differences in the anatomy and physiology of the respiratory tract, results of animal experiments evaluating inhaled formulations are often questioned. Furthermore, although great progress in animal models for asthma, COPD and CF has been made with the genetic modifications of animals, there is still great space and a huge need for advancements in terms of representative infection models associated with the relevant diseases to adequately reflect the pathological features of the diseased lungs. A significant drawback related to animal experiments is that they usually cannot provide direct information on how to further improve the formulation design to the level that (advanced) in vitro models can provide.

Recently, the convergence of microfluidic devices and cocultured cell models gives rise to organ-on-a-chip technologies, which creates "dynamic models" emulating in vivo physiological functions and pharmacological responses [177], thus enabling researchers to gain human relevant data in a more "highthroughput" manner [85]. Recent advances in microsystems engineering have made it possible to create biomimetic microchips accurately recapitulating the features of COPD, including lung inflammation (e.g., cytokine hypersecretion and increased neutrophil recruitment), and acute exacerbations by exposure to pathogens [178-180]. In addition to precisely recreate functions of organs, microfluidic chips can be easily integrated with a variety of advanced techniques (e.g., high-resolution microscopy) for a fundamental understanding of the complex interplays between nanoparticles and the distinct biological elements of the organs. Therefore, organ-on-a-chip technology may represent a promising approach to increase the success ratio of translating exploratory research to clinical trials.

In addition, from a translational point of view, nanoparticle-based formulations possess a variety of challenges for clinical use. For example, nanoparticle-based formulations are usually administered via nebulization in clinic, yet the potential impact of the shear and thermal stresses involved in the nebulization process of the nanoformulation has long been recognized. For example, it is well known that nebulization can lead to drug leakage and aggregation of nanoparticles. In this regard, engineering the nanoparticles into a microparticle-based formulation (known as Trojan particles or nanoembedded microparticles) may represent an effective approach to solve the issue by integrating the advantages of both micro- and nano-sized formulations [181, 182].

\section{Conclusions}

The insufficient possibilities in terms of therapeutic options to treat chronic and persistent respiratory tract bacterial infections remain a major threat to human health worldwide. Nanoparticle-mediated aerosol antimicrobial therapies may pave the way for breakthroughs, yet sufficient improvements in efficacy requires their effective penetration through the mucus and localization adequately close to the bacteria, followed by release of sufficient amounts of antimicrobials to maintain a favorable pharmacokinetics/pharmacodynamics (PK/PD) profile at the site of action. To date, the progress in the fields of materials science and nanotechnology has led to a variety of innovative nanoparticle-based drug delivery systems with controllable properties, which potentially allow for effectively overcoming the delivery barriers and improving the PK/PD at the site of action. However, the majority of studies are still in the early stages of the drug development process and translation to both industrial production scale and in vivo testing needs addressing. To prompt the translation from exploratory research to clinical application, there are still many challenges to be addressed, especially the lack of representative disease- and infection-specific in vivo models. Also, specific guidelines and regulations regarding nanotechnologybased products related to developing new tools, standards, and approaches to assess safety, efficacy, quality, and performance of such products are urgently needed. Overcoming the aforementioned obstacles will lead to safer and more efficient nanoparticle-mediated aerosol antimicrobial therapy entering the clinical phases of drug development. 
Author contribution Feng Wan and Hanne Mørck Nielsen received the invitation from the guest editor and had the idea for the article. Zheng Huang, Sylvia Natalie Kłodzińska and Feng Wan performed the literature search and drafted the manuscript. Hanne Mørck Nielsen critically revised the work.

Funding This study is financially supported by the Novo Nordisk Foundation (Grand Challenge Program; NNF16OC0021948) and the Lundbeck Foundation (R264-2017-3404).

\section{Declarations}

Competing interests The authors declare that they have no conflict of interest.

\section{References}

1. Troeger C, Blacker B, Khalil IA, Rao PC, Cao J, Zimsen SRM, et al. Estimates of the global, regional, and national morbidity, mortality, and aetiologies of lower respiratory infections in 195 countries, 1990-2016: a systematic analysis for the Global Burden of Disease Study 2016. Lancet Infect Dis. 2018;18(11):1191210. https://doi.org/10.1016/s1473-3099(18)30310-4.

2. Wang H, Naghavi M, Allen C, Barber RM, Bhutta ZA, Carter A, et al. Global, regional, and national life expectancy, all-cause mortality, and cause-specific mortality for 249 causes of death, 1980-2015: a systematic analysis for the Global Burden of Disease Study 2015. Lancet. 2016;388(10053):1459-544. https:// doi.org/10.1016/s0140-6736(16)31012-1.

3. van Doorn HR, Yu H. Viral respiratory infections. 05/28 ed. Hunter's tropical medicine and emerging infectious diseases. 2020. https://doi.org/10.1016/B978-0-323-55512-8.00033-8.

4. Chakravarty M, Vora A. Nanotechnology-based antiviral therapeutics. Drug Deliv Transl Res. 2020;3:1-40. https://doi. org/10.1007/s13346-020-00818-0.

5. Klinger-Strobel M, Lautenschlager C, Fischer D, Mainz JG, Bruns T, Tuchscherr L, et al. Aspects of pulmonary drug delivery strategies for infections in cystic fibrosis-where do we stand? Expert Opin Drug Deliv. 2015;12(8):1351-74. https:// doi.org/10.1517/17425247.2015.1007949.

6. Andrade F, Rafael D, Videira M, Ferreira D, Sosnik A, Sarmento B. Nanotechnology and pulmonary delivery to overcome resistance in infectious diseases. Adv Drug Deliv Rev. 2013;65(1314):1816-27. https://doi.org/10.1016/j.addr.2013.07.020.

7. Dudley MN, Loutit J, Griffith DC. Aerosol antibiotics: considerations in pharmacological and clinical evaluation. Curr Opin Biotechnol. 2008;19(6):637-43. https://doi.org/10.1016/j.copbio. 2008.11.002.

8. Drenkard E, Ausubel FM. Pseudomonas biofilm formation and antibiotic resistance are linked to phenotypic variation. Nature. 2002;416:740-3.

9. Hoffman LR, D'Argenio DA, MacCoss MJ, Zhang Z, Jones RA, Miller SI. Aminoglycoside antibiotics induce bacterial biofilm formation. Nature. 2005;436(7054):1171-5. https://doi. org/10.1038/nature03912.

10. Abed N, Couvreur P. Nanocarriers for antibiotics: a promising solution to treat intracellular bacterial infections. Int J Antimicrob Agents. 2014;43(6):485-96. https://doi.org/10.1016/j. ijantimicag.2014.02.009.

11. Huh AJ, Kwon YJ. Nanoantibiotics": a new paradigm for treating infectious diseases using nanomaterials in the antibiotics resistant era. J Control Release. 2011;156(2):128-45. https:// doi.org/10.1016/j.jconrel.2011.07.002.

12. Pelgrift RY, Friedman AJ. Nanotechnology as a therapeutic tool to combat microbial resistance. Adv Drug Deliv Rev. 2013;65(13-14):1803-15. https://doi.org/10.1016/j. addr.2013.07.011.

13. Ratjen F, Döring G. Cystic fibrosis. Lancet. 2003;361(9358):6819. https://doi.org/10.1016/s0140-6736(03)12567-6.

14. Smith JJ, Travis SM, Greenberg EP, Welsh MJ. Cystic fibrosis airway epithelia fail to kill bacteria because of abnormal airway surface fluid. Cell. 1996;85(2):229-36. https://doi.org/10.1016/ s0092-8674(00)81099-5.

15. Smyth AR, Bell SC, Bojcin S, Bryon M, Duff A, Flume P, et al. European Cystic Fibrosis Society Standards of Care: Best Practice guidelines. J Cyst Fibros. 2014;13(Suppl 1):S23-42. https:// doi.org/10.1016/j.jcf.2014.03.010.

16. Lozano R, Naghavi M, Foreman K, Lim S, Shibuya K, Aboyans V, et al. Global and regional mortality from 235 causes of death for 20 age groups in 1990 and 2010: a systematic analysis for the Global Burden of Disease Study 2010. Lancet. 2012;380(9859):2095128. https://doi.org/10.1016/s0140-6736(12)61728-0.

17. Soriano JB, Abajobir AA, Abate KH, Abera SF, Agrawal A, Ahmed MB, et al. Global, regional, and national deaths, prevalence, disability-adjusted life years, and years lived with disability for chronic obstructive pulmonary disease and asthma, 1990-2015: a systematic analysis for the Global Burden of Disease Study 2015. Lancet Respir Med. 2017;5(9):691-706. https:// doi.org/10.1016/s2213-2600(17)30293-x.

18. Vos T, Allen C, Arora M, Barber RM, Bhutta ZA, Brown A, et al. Global, regional, and national incidence, prevalence, and years lived with disability for 310 diseases and injuries, 1990-2015: a systematic analysis for the Global Burden of Disease Study 2015. Lancet. 2016;388(10053):1545-602. https://doi.org/10.1016/ s0140-6736(16)31678-6.

19. Sethi S. Infection as a comorbidity of COPD. Eur Respir J. 2010;35(6):1209-15. https://doi.org/10.1183/09031936.00081409.

20. Murphy TF, Brauer AL, Eschberger K, Lobbins P, Grove L, Cai $\mathrm{X}$, et al. Pseudomonas aeruginosa in chronic obstructive pulmonary disease. Am J Respir Crit Care Med. 2008;177(8):853-60. https://doi.org/10.1164/rccm.200709-1413OC.

21. Martinez-Solano L, Macia MD, Fajardo A, Oliver A, Martinez JL. Chronic Pseudomonas aeruginosa infection in chronic obstructive pulmonary disease. Clin Infect Dis. 2008;47(12):1526-33. https:// doi.org/10.1086/593186.

22. Garcia-Nuñez M, Marti S, Puig C, Perez-Brocal V, Millares L, Liñares $\mathrm{F}$, et al. Influence of biofim on the bronchial microbiome in COPD patients colonized or infected by pseudomonas aeruginosa. Eur Respir J. 2015;46(suppl 59):PA5028. https://doi. org/10.1183/13993003.congress-2015.PA5028.

23. Staykova T, Black PN, Chacko EE, Poole P. Prophylactic antibiotic therapy for chronic bronchitis. Cochrane Database Syst Rev. 2003(1):CD004105. https://doi.org/10.1002/14651858.CD004105.

24. Organization WH. Global Tuberculosis Report 2019: World Health Organization, WHO2019.

25. Dheda K, Gumbo T, Maartens G, Dooley KE, McNerney R, Murray M, et al. The epidemiology, pathogenesis, transmission, diagnosis, and management of multidrug-resistant, extensively drug-resistant, and incurable tuberculosis. Lancet Respir Med. 2017. https://doi.org/10.1016/s2213-2600(17)30079-6.

26. Dookie N, Rambaran S, Padayatchi N, Mahomed S, Naidoo $\mathrm{K}$. Evolution of drug resistance in Mycobacterium tuberculosis: a review on the molecular determinants of resistance and implications for personalized care. J Antimicrob Chemother. 2018;73(5):1138-51. https://doi.org/10.1093/jac/dkx506.

27. Guirado E, Schlesinger LS. Modeling the Mycobacterium tuberculosis granuloma - the critical battlefield in host 
immunity and disease. Front Immunol. 2013;4:98. https://doi. org/10.3389/fimmu.2013.00098.

28. Dartois V, Barry CE. Clinical pharmacology and lesion penetrating properties of second- and third-line antituberculous agents used in the management of multidrug-resistant (MDR) and extensively-drug resistant (XDR) tuberculosis. Curr Clin Pharmacol. 2010;5(2):96-114. https://doi.org/10.2174/157488410791110797.

29. Dartois V. The path of anti-tuberculosis drugs: from blood to lesions to mycobacterial cells. Nat Rev Microbiol. 2014;12(3):159-67. https://doi.org/10.1038/nrmicro3200.

30. Imam JS, Duarte AG. Non-CF bronchiectasis: Orphan disease no longer. Respir Med. 2020;166. https://doi.org/10.1016/j. rmed.2020.105940.

31. Chalmers JD, Hill AT. Mechanisms of immune dysfunction and bacterial persistence in non-cystic fibrosis bronchiectasis. Mol Immunol. 2013;55(1):27-34. https://doi.org/10.1016/j. molimm.2012.09.011.

32. Tunney MM, Einarsson GG, Wei L, Drain M, Klem ER, Cardwell $\mathrm{C}$, et al. Lung microbiota and bacterial abundance in patients with bronchiectasis when clinically stable and during exacerbation. Am J Respir Crit Care Med. 2013;187(10):1118-26. https://doi. org/10.1164/rccm.201210-1937oc.

33. Hunter JD. Ventilator associated pneumonia. BMJ. 2012;344(may29 1):e3325-e. https://doi.org/10.1136/bmj.e3325.

34. Mandell LA. Community-acquired pneumonia: an overview. Postgrad Med. 2015;127(6):607-15. https://doi. org/10.1080/00325481.2015.1074030.

35. Priftis KN, Litt D, Manglani S, Anthracopoulos MB, Thickett K, Tzanakaki G, et al. Bacterial bronchitis caused by Streptococcus pneumoniae and nontypable Haemophilus influenzae in children. Chest. 2013;143(1):152-7. https://doi.org/10.1378/ chest.12-0623.

36. Ng AW, Bidani A, Heming TA. Innate host defense of the lung: effects of lung-lining fluid pH. Lung. 2004;182(5):297-317. https:// doi.org/10.1007/s00408-004-2511-6.

37. Williams OW, Sharafkhaneh A, Kim V, Dickey BF, Evans $\mathrm{CM}$. Airway mucus: from production to secretion. Am J Respir Cell Mol Biol. 2006;34(5):527-36. https://doi.org/10.1165/ rcmb.2005-0436SF.

38. Fahy JV, Dickey BF. Airway mucus function and dysfunction. N Engl J Med. 2010;363(10):2233-47.

39. Thornton DJ, Sheehan JK. From mucins to mucus: toward a more coherent understanding of this essential barrier. Proc Am Thorac Soc. 2004;1(1):54-61. https://doi.org/10.1513/pats.2306016.

40. Cun D, Wan F, Yang M. Formulation strategies and particle engineering technologies for pulmonary delivery of biopharmaceuticals. Curr Pharm Des. 2015;21:2599-610.

41. Tate S, MacGregor G, Davis M, Innes J, Greening A. Airways in cystic fibrosis are acidified: detection by exhaled breath condensate. Thorax. 2002;57(11):926-9.

42. Poschet J, Perkett E, Deretic V. Hyperacidification in cystic fibrosis: links with lung disease and new prospects for treatment. Trends Mol Med. 2002;8(11):512-9.

43. Bodem CR, Lampton LM, Miller DP, Tarka EF, Everett ED. Endobronchial $\mathrm{pH}$. Relevance of aminoglycoside activity in gram-negative bacillary pneumonia. Am Rev Respir Dis. 1983;127(39-41).

44. Hong Z, Chasan B, Bansil R, Turner BS, Bhaskar KR, Afdhal $\mathrm{NH}$. Atomic force microscopy reveals aggregation of gastric mucin at low pH. Biomacromolecules. 2005;6(6):3458-66.

45. Celli JP, Turner BS, Afdhal NH, Ewoldt RH, McKinley GH, Bansil R, et al. Rheology of gastric mucin exhibits a pH-dependent sol-gel transition. Biomacromolecules. 2007;8(5):1580-6.

46. Cao X, Bansil R, Bhaskar KR, Turner BS, LaMont JT, Niu N, et al. $\mathrm{pH}$-dependent conformational change of gastric mucin leads to sol-gel transition. Biophys J. 1999;76(3):1250-8.
47. Wan F, Herzberg M, Huang Z, Hassenkam T, Nielsen HM. A free-floating mucin layer to investigate the effect of the local microenvironment in lungs on mucin-nanoparticle interactions. Acta Biomater. 2020. https://doi.org/10.1016/j.actbio. 2020.01.014.

48. Labiris NR, Dolovich MB. Pulmonary drug delivery. Part I: physiological factors affecting therapeutic effectiveness of aerosolized medications. Br J Clin Pharmacol. 2003;56(6):588-99. https://doi.org/10.1046/j.1365-2125.2003.01892.x

49. Parra E, Perez-Gil J. Composition, structure and mechanical properties define performance of pulmonary surfactant membranes and films. Chem Phys Lipids. 2015;185C:153-75. https:// doi.org/10.1016/j.chemphyslip.2014.09.002.

50. Garcia-Diaz M, Birch D, Wan F, Nielsen HM. The role of mucus as an invisible cloak to transepithelial drug delivery by nanoparticles. Adv Drug Deliv Rev. 2018;124:107-24. https://doi. org/10.1016/j.addr.2017.11.002.

51. Griese M. Pulmonary surfactant in health and human lung diseases: state of the art. Eur Respir J. 1999;13(6):1455-76.

52. Wan F, Nylander T, Foged C, Yang M, Baldursdottir SG, Nielsen HM. Qualitative and quantitative analysis of the biophysical interaction of inhaled nanoparticles with pulmonary surfactant by using quartz crystal microbalance with dissipation monitoring. J Colloid Interface Sci. 2019;545:162-71. https://doi. org/10.1016/j.jcis.2019.02.088.

53. Hall-Stoodley L, Costerton JW, Stoodley P. Bacterial biofilms: from the natural environment to infectious diseases. Nat Rev Microbiol. 2004;2(2):95-108. https://doi.org/10.1038/nrmicro821.

54. Flemming HC, Wingender J. The biofilm matrix. Nat Rev Microbiol. 2010;8(9):623-33. https://doi.org/10.1038/nrmicro2415.

55. Costerton JW, Stewart PS, Greenberg EP. Bacterial biofilms: a common cause of persistent infections. Science. 1999;284(5418):1318-22.

56. Ciofu O, Tolker-Nielsen T, Jensen PO, Wang H, Hoiby N. Antimicrobial resistance, respiratory tract infections and role of biofilms in lung infections in cystic fibrosis patients Adv Drug Deliv Rev. 2015;85:7-23. https://doi.org/10.1016/j.addr.2014.11.017.

57. Levy SB, Marshall B. Antibacterial resistance worldwide: causes, challenges and responses. Nat Med. 2004;10(12 Suppl):S122-9. https://doi.org/10.1038/nm1145.

58. Rasko DA, Sperandio V. Anti-virulence strategies to combat bacteriamediated disease. Nat Rev Drug Discov. 2010;9(2):117-28. https:// doi.org/10.1038/nrd3013.

59. Kamaruzzaman NF, Kendall S, Good L. Targeting the hard to reach: challenges and novel strategies in the treatment of intracellular bacterial infections. Br J Pharmacol. 2017;174(14):222536. https://doi.org/10.1111/bph.13664.

60. Armstrong JA, Hart PD. Response of cultured macrophages to Mycobacterium tuberculosis, with observations on fusion of lysosomes with phagosomes. J Exp Med. 1971;134(3 Pt 1):713-40. https://doi.org/10.1084/jem.134.3.713.

61. Watson RO, Manzanillo PS, Cox JS. Extracellular M. tuberculosis DNA targets bacteria for autophagy by activating the host DNA-sensing pathway. Cell. 2012;150(4):803-15. https://doi. org/10.1016/j.cell.2012.06.040.

62. Mayaud C, Mangiapan G. Role of intracellular pathogens in respiratory tract infections Clin Microbiol Infect. 1998;4(Suppl 4):S14-s22.

63. Ladaviere C, Gref R. Toward an optimized treatment of intracellular bacterial infections: input of nanoparticulate drug delivery systems. Nanomedicine (Lond). 2015;10(19):3033-55. https:// doi.org/10.2217/nnm.15.128.

64. Garzoni C, Kelley WL. Staphylococcus aureus: new evidence for intracellular persistence. Trends Microbiol. 2009;17(2):59-65. https://doi.org/10.1016/j.tim.2008.11.005.

65. Angus AA, Lee AA, Augustin DK, Lee EJ, Evans DJ, Fleiszig SM. Pseudomonas aeruginosa induces membrane blebs in 
epithelial cells, which are utilized as a niche for intracellular replication and motility. Infect Immun. 2008;76(5):1992-2001. https://doi.org/10.1128/iai.01221-07.

66. Schmiedl A, Kerber-Momot T, Munder A, Pabst R, Tschernig T. Bacterial distribution in lung parenchyma early after pulmonary infection with Pseudomonas aeruginosa. Cell Tissue Res. 2010;342(1):67-73. https://doi.org/10.1007/s00441-010-1036-y.

67. Rathman M, Sjaastad MD, Falkow S. Acidification of phagosomes containing Salmonella typhimurium in murine macrophages. Infect Immun. 1996;64(7):2765-73. https://doi. org/10.1128/iai.64.7.2765-2773.1996.

68. Lemaire S, Tulkens PM, Van Bambeke F. Contrasting effects of acidic $\mathrm{pH}$ on the extracellular and intracellular activities of the anti-gram-positive fluoroquinolones moxifloxacin and delafloxacin against Staphylococcus aureus. Antimicrob Agents Chemother. 2011;55(2):649-58. https://doi.org/10.1128/aac.01201-10.

69. Grant SS, Hung DT. Persistent bacterial infections, antibiotic tolerance, and the oxidative stress response. Virulence. 2013;4(4):273-83. https://doi.org/10.4161/viru.23987.

70. Wayne LG, Sohaskey CD. Nonreplicating persistence of mycobacterium tuberculosis. Annu Rev Microbiol. 2001;55:139-63. https://doi.org/10.1146/annurev.micro.55.1.139.

71. Rejman J, Oberle V, Zuhorn IS, Hoekstra D. Size-dependent internalization of particles via the pathways of clathrin- and caveolaemediated endocytosis. Biochem J. 2004;377(Pt 1):159-69. https:// doi.org/10.1042/bj20031253.

72. Jiang W, Kim BY, Rutka JT, Chan WC. Nanoparticle-mediated cellular response is size-dependent. Nat Nanotechnol. 2008;3(3):145-50. https://doi.org/10.1038/nnano.2008.30.

73. Peulen TO, Wilkinson KJ. Diffusion of nanoparticles in a biofilm. Environ Sci Technol. 2011;45(8):3367-73. https://doi. org/10.1021/es103450g.

74. Geng Y, Dalhaimer P, Cai S, Tsai R, Tewari M, Minko T, et al. Shape effects of filaments versus spherical particles in flow and drug delivery. Nat Nanotechnol. 2007;2(4):249-55. https://doi. org/10.1038/nnano.2007.70

75. Champion JA, Katare YK, Mitragotri S. Particle shape: a new design parameter for micro- and nanoscale drug delivery carriers. J Control Release. 2007;121(1-2):3-9. https://doi.org/10.1016/j. jconrel.2007.03.022.

76. Gessner A, Lieske A, Paulke B, Müller R. Influence of surface charge density on protein adsorption on polymeric nanoparticles: analysis by two-dimensional electrophoresis. Eur J Pharm Biopharm. 2002;54(2):165-70. https://doi.org/10.1016/s09396411(02)00081-4.

77. Jones MC, Jones SA, Riffo-Vasquez Y, Spina D, Hoffman E, Morgan A, et al. Quantitative assessment of nanoparticle surface hydrophobicity and its influence on pulmonary biocompatibility. J Control Release. 2014;183:94-104. https://doi.org/10.1016/j. jconrel.2014.03.022.

78. Valle RP, Huang CL, Loo JSC, Zuo YY. Increasing hydrophobicity of nanoparticles intensifies lung surfactant film inhibition and particle retention. ACS Sustain Chem Eng. 2014;2(7):1574-80. https://doi.org/10.1021/sc500100b.

79. Suk JS, Lai SK, Wang YY, Ensign LM, Zeitlin PL, Boyle MP, et al. The penetration of fresh undiluted sputum expectorated by cystic fibrosis patients by non-adhesive polymer nanoparticles. Biomaterials. 2009;30(13):2591-7. https://doi.org/10.1016/j. biomaterials.2008.12.076.

80. Forier K, Messiaen AS, Raemdonck K, Nelis H, De Smedt S, Demeester J, et al. Probing the size limit for nanomedicine penetration into Burkholderia multivorans and Pseudomonas aeruginosa biofilms. J Control Release. 2014;195:21-8. https://doi. org/10.1016/j.jconrel.2014.07.061.

81. Olmsted SS, Padgett JL, Yudin AI, Whaley KJ, Moench TR, Cone RA. Diffusion of macromolecules and virus-like particles in human cervical mucus. Biophys J. 2001;81(4):1930-7. https:// doi.org/10.1016/S0006-3495(01)75844-4.

82. Pereira de Sousa I, Steiner C, Schmutzler M, Wilcox MD, Veldhuis GJ, Pearson JP et al. Mucus permeating carriers: formulation and characterization of highly densely charged nanoparticles. Eur J Pharm Biopharm. 2015;97(Pt A):273-9. https://doi.org/10.1016/j. ejpb.2014.12.024.

83. Wan F, Nylander T, Klodzinska SN, Foged C, Yang M, Baldursdottir $\mathrm{SG}$, et al. Lipid shell-enveloped polymeric nanoparticles with high integrity of lipid shells improve mucus penetration and interaction with cystic fibrosis-related bacterial biofilms. ACS Appl Mater Interfaces. 2018;10(13):10678-87. https://doi.org/10.1021/acsami. $7 \mathrm{~b} 19762$.

84. Al-Nemrawi NK, Alshraiedeh NH, Zayed AL, Altaani BM. Low molecular weight chitosan-coated PLGA nanoparticles for pulmonary delivery of tobramycin for cystic fibrosis. Pharmaceuticals (Basel). 2018;11(1). https://doi.org/10.3390/ph11010028.

85. Benam KH, Konigshoff M, Eickelberg O. Breaking the in vitro barrier in respiratory medicine. Engineered microphysiological systems for chronic obstructive pulmonary disease and beyond. Am J Respir Crit Care Med. 2018;197(7):869-75. https://doi. org/10.1164/rccm.201709-1795PP.

86. Baranyai Z. Fighting against intracellular pathogens: host celltargeted drug delivery. Future Microbiol. 2020;15:833-6. https:// doi.org/10.2217/fmb-2020-0047.

87. Guo S, Huang L. Nanoparticles escaping RES and endosome: challenges for siRNA delivery for cancer therapy. J Nanomater. 2011;2011:1-12. https://doi.org/10.1155/2011/742895.

88. Viswanathan V, Pharande R, Bannalikar A, Gupta P, Gupta U, Mukne A. Inhalable liposomes of Glycyrrhiza glabra extract for use in tuberculosis: formulation, in vitro characterization, in vivo lung deposition, and in vivo pharmacodynamic studies. Drug Dev Ind Pharm. 2019;45(1):11-20. https://doi.org/10.1080/03639045. 2018.1513025.

89. Derbali RM, Aoun V, Moussa G, Frei G, Tehrani SF, Del'Orto JC, et al. Tailored nanocarriers for the pulmonary delivery of levofloxacin against Pseudomonas aeruginosa: a comparative study. Mol Pharm. 2019;16(5):1906-16. https://doi.org/10.1021/ acs.molpharmaceut.8b01256.

90. Gupta PV, Nirwane AM, Nagarsenker MS. Inhalable levofloxacin liposomes complemented with lysozyme for treatment of pulmonary infection in rats: effective antimicrobial and antibiofilm strategy. AAPS PharmSciTech. 2018;19(3):1454-67. https://doi. org/10.1208/s12249-017-0945-4.

91. Li Y, Tang C, Zhang E, Yang L. Electrostatically entrapped colistin liposomes for the treatment of Pseudomonas aeruginosa infection. Pharm Dev Technol. 2017;22(3):436-44. https://doi. org/10.1080/10837450.2016.1228666.

92. Sabaeifard P, Abdi-Ali A, Gamazo C, Irache JM, Soudi MR. Improved effect of amikacin-loaded poly(D, L-lactide-coglycolide) nanoparticles against planktonic and biofilm cells of Pseudomonas aeruginosa. J Med Microbiol. 2017;66(2):137-48. https://doi.org/10.1099/jmm.0.000430.

93. Wan F, Bohr SSR, Kłodzińska SN, Jumaa H, Huang Z, Nylander $\mathrm{T}$, et al. Ultra-small TPGS-PLGA Hybrid nanoparticles for site-specific delivery of antibiotics into pseudomonas aeruginosa biofilms in lungs. Acs Appl Mater Inter. 2019. https://doi. org/10.1021/acsami.9b19644.

94. Baelo A, Levato R, Julián E, Crespo A, Astola J, Gavaldà J, et al. Disassembling bacterial extracellular matrix with DNase-coated nanoparticles to enhance antibiotic delivery in biofilm infections. J Control Release. 2015;209:150-8. https://doi.org/10.1016/j. jconrel.2015.04.028.

95. Patel KK, Tripathi M, Pandey N, Agrawal AK, Gade S, Anjum $\mathrm{MM}$, et al. Alginate lyase immobilized chitosan nanoparticles of ciprofloxacin for the improved antimicrobial activity against 
the biofilm associated mucoid $\mathrm{P}$. aeruginosa infection in cystic fibrosis. Int J Pharm. 2019;563:30-42. https://doi.org/10.1016/j. ijpharm.2019.03.051.

96. Kłodzińska SN, Pletzer D, Rahanjam N, Rades T, Hancock REW, Nielsen HM. Hyaluronic acid-based nanogels improve in vivo compatibility of the anti-biofilm peptide DJK-5. Nanomedicine. 2019;20:102022. https://doi.org/10.1016/j.nano.2019.102022.

97. Klodzinska SN, Wan F, Jumaa H, Sternberg C, Rades T, Nielsen HM. Utilizing nanoparticles for improving anti-biofilm effects of azithromycin: a head-to-head comparison of modified hyaluronic acid nanogels and coated poly (lactic-co-glycolic acid) nanoparticles. J Colloid Interface Sci. 2019;555:595-606. https:// doi.org/10.1016/j.jcis.2019.08.006.

98. Kłodzińska SN, Molchanova N, Franzyk H, Hansen PR, Damborg $\mathrm{P}$, Nielsen HM. Biopolymer nanogels improve antibacterial activity and safety profile of a novel lysine-based $\alpha$-peptide/ $\beta$-peptoid peptidomimetic. Eur J Pharm Biopharm. 2018;128:1-9. https:// doi.org/10.1016/j.ejpb.2018.03.012.

99. Simonson AW, Lawanprasert A, Goralski TDP, Keiler KC, Medina SH. Bioresponsive peptide-polysaccharide nanogels - a versatile delivery system to augment the utility of bioactive cargo. Nanomedicine. 2019;17:391-400. https://doi. org/10.1016/j.nano.2018.10.008.

100. Silva JP, Gonçalves C, Costa C, Sousa J, Silva-Gomes R, Castro AG, et al. Delivery of LLKKK18 loaded into self-assembling hyaluronic acid nanogel for tuberculosis treatment. J Control Release. 2016;235:112-24. https://doi.org/10.1016/j.jconrel. 2016.05.064.

101. Deacon J, Abdelghany SM, Quinn DJ, Schmid D, Megaw J, Donnelly $\mathrm{RF}$, et al. Antimicrobial efficacy of tobramycin polymeric nanoparticles for Pseudomonas aeruginosa infections in cystic fibrosis: formulation, characterisation and functionalisation with dornase alfa (DNase). J Control Release. 2015;198:55-61. https://doi.org/10.1016/j.jconrel. 2014.11.022.

102. Petkar KC, Chavhan S, Kunda N, Saleem I, Somavarapu S, Taylor KMG, et al. Development of novel octanoyl chitosan nanoparticles for improved rifampicin pulmonary delivery: optimization by factorial design. AAPS PharmSciTech. 2018;19(4):1758-72. https://doi.org/10.1208/s12249-018-0972-9.

103. Wu T, Liao W, Wang W, Zhou J, Tan W, Xiang W, et al. Genipin-crosslinked carboxymethyl chitosan nanogel for lungtargeted delivery of isoniazid and rifampin. Carbohydr Polym. 2018;197:403-13. https://doi.org/10.1016/j.carbpol.2018.06.034.

104. Scolari IR, Paez PL, Sanchez-Borzone ME, Granero GE. Promising chitosan-coated alginate-Tween 80 nanoparticles as rifampicin coadministered ascorbic acid delivery carrier against Mycobacterium tuberculosis. AAPS PharmSciTech. 2019;20(2):67. https://doi.org/10.1208/s12249-018-1278-7.

105. Huang YC, Li RY, Chen JY, Chen JK. Biphasic release of gentamicin from chitosan/fucoidan nanoparticles for pulmonary delivery. Carbohydr Polym. 2016;138:114-22. https://doi. org/10.1016/j.carbpol.2015.11.072.

106. Popov A, Schopf L, Bourassa J, Chen H. Enhanced pulmonary delivery of fluticasone propionate in rodents by mucuspenetrating nanoparticles. Int J Pharm. 2016;502(1-2):188-97. https://doi.org/10.1016/j.ijpharm.2016.02.031.

107. Sachetelli S, Khalil H, Chen T, Beaulac C, Sénéchal S, Lagacé J. Demonstration of a fusion mechanism between a fluid bactericidal liposomal formulation and bacterial cells. Biochim Biophys Acta. 2000;1463(2):254-66. https://doi.org/10.1016/ S0005-2736(99)00217-5.

108. Yu T, Chan KW, Anonuevo A, Song X, Schuster BS, Chattopadhyay $\mathrm{S}$, et al. Liposome-based mucus-penetrating particles (MPP) for mucosal theranostics: demonstration of diamagnetic chemical exchange saturation transfer (diaCEST) magnetic resonance imaging
(MRI). Nanomedicine. 2015;11(2):401-5. https://doi.org/10.1016/j. nano.2014.09.019.

109. Meers P, Neville M, Malinin V, Scotto AW, Sardaryan G, Kurumunda R, et al. Biofilm penetration, triggered release and in vivo activity of inhaled liposomal amikacin in chronic Pseudomonas aeruginosa lung infections. J Antimicrob Chemother. 2008;61(4):859-68. https://doi.org/10.1093/jac/dkn059.

110. Zhang J, Leifer F, Rose S, Chun DY, Thaisz J, Herr T, et al. Amikacin liposome inhalation suspension (ALIS) penetrates non-tuberculous mycobacterial biofilms and enhances amikacin uptake into macrophages. Front Microbiol. 2018;9(915). https://doi.org/10.3389/fmicb.2018.00915.

111. Kale AA, Torchilin VP. Enhanced transfection of tumor cells in vivo using "Smart" $\mathrm{pH}$-sensitive TAT-modified pegylated liposomes. J Drug Target. 2007;15(7-8):538-45. https://doi. org/10.1080/10611860701498203.

112. Nie Y, Gunther M, Gu Z, Wagner E. Pyridylhydrazone-based PEGylation for $\mathrm{pH}$-reversible lipopolyplex shielding. Biomaterials. 2011;32(3):858-69. https://doi.org/10.1016/j.biomaterials. 2010.09.032.

113. Forier K, Raemdonck K, De Smedt SC, Demeester J, Coenye T, Braeckmans K. Lipid and polymer nanoparticles for drug delivery to bacterial biofilms. J Control Release. 2014;190:607-23.

114. Hill KJ, Kaszuba M, Creeth JE, Jones MN. Reactive liposomes encapsulating a glucose oxidase-peroxidase system with antibacterial activity. Biochim Biophys Acta Biomembr. 1997;1326(1):37-46. https://doi.org/10.1016/S0005-2736(97)00007-2.

115. Jones MN, Kaszuba M, Reboiras MD, Lyle IG, Hill KJ, Song $\mathrm{YH}$, et al. The targeting of phospholipid liposomes to bacteria. Biochim Biophys Acta. 1994;1196(1):57-64. https://doi. org/10.1016/0005-2736(94)90295-x.

116. Kim H-J, Michael Gias EL, Jones MN. The adsorption of cationic liposomes to Staphylococcus aureus biofilms. Colloids Surf A Physicochem Eng Asp. 1999;149(1):561-70. https:// doi.org/10.1016/S0927-7757(98)00765-1.

117. Jones MN, Song YH, Kaszuba M, Reboiras MD. The interaction of phospholipid liposomes with bacteria and their use in the delivery of bactericides. J Drug Target. 1997;5(1):25-34. https://doi.org/10.3109/10611869708995855.

118. Robinson AM, Creeth JE, Jones MN. The specificity and affinity of immunoliposome targeting to oral bacteria. Biochim Biophys Acta. 1998;1369(2):278-86. https://doi.org/10.1016/ s0005-2736(97)00231-9.

119. Jones MN, Francis SE, Hutchinson FJ, Handley PS, Lyle IG. Targeting and delivery of bactericide to adsorbed oral bacteria by use of proteoliposomes. Biochim Biophys Acta. 1993;1147(2):251-61. https://doi.org/10.1016/00052736(93)90010-w.

120. Yang K, Gitter B, Rüger R, Albrecht V, Wieland GD, Fahr A. Wheat germ agglutinin modified liposomes for the photodynamic inactivation of bacteria. Photochem Photobiol. 2012;88(3):54856. https://doi.org/10.1111/j.1751-1097.2011.00983.x.

121. Irache JM, Salman HH, Gamazo C, Espuelas S. Mannose-targeted systems for the delivery of therapeutics. Expert Opin Drug Deliv. 2008;5(6):703-24. https://doi.org/10.1517/17425247.5.6.703.

122. Makadia HK, Siegel SJ. Poly lactic-co-glycolic acid (PLGA) as biodegradable controlled drug delivery carrier. Polymers. 2011;3(3):1377-97. https://doi.org/10.3390/polym3031377.

123. Coowanitwong I, Arya V, Kulvanich P, Hochhaus G. Slow release formulations of inhaled rifampin. AAPS J. 2008;10(2):342-8. https://doi.org/10.1208/s12248-008-9044-5.

124. Ungaro F, d'Angelo I, Coletta C, d'Emmanuele di Villa Bianca R, Sorrentino R, Perfetto B, et al. Dry powders based on PLGA nanoparticles for pulmonary delivery of antibiotics: modulation of encapsulation efficiency, release rate and lung deposition pattern 
by hydrophilic polymers. J Control Release. 2012;157(1):14959. https://doi.org/10.1016/j.jconrel.2011.08.010.

125. Jensen DK, Jensen LB, Koocheki S, Bengtson L, Cun D, Nielsen $\mathrm{HM}$, et al. Design of an inhalable dry powder formulation of DOTAP-modified PLGA nanoparticles loaded with siRNA. J Control Release. 2012;157(1):141-8. https://doi.org/10.1016/j. jconrel.2011.08.011.

126. De Stefano D, Ungaro F, Giovino C, Polimeno A, Quaglia F, Carnuccio R. Sustained inhibition of IL-6 and IL-8 expression by decoy ODN to NF- $\mathrm{KB}$ delivered through respirable large porous particles in LPS-stimulated cystic fibrosis bronchial cells. J Gene Med. 2011;13(4):200-8. https://doi.org/10.1002/jgm.1546.

127. Ungaro F, De Stefano D, Giovino C, Masuccio A, Miro A, Sorrentino $\mathrm{R}$, et al. PEI-engineered respirable particles delivering a decoy oligonucleotide to NF- $\mathrm{kB}$ : inhibiting MUC2 expression in LPS-stimulated airway epithelial cells. PloS one. 2012;7(10):e46457. https://doi. org/10.1371/journal.pone.0046457.

128. Horváti K, Gyulai G, Csámpai A, Rohonczy J, Kiss É, Bősze S. Surface Layer modification of poly(d, 1-lactic-co-glycolic acid) nanoparticles with targeting peptide: a convenient synthetic route for Pluronic F127Tuftsin conjugate. Bioconjug Chem. 2018;29(5):1495-9. https:// doi.org/10.1021/acs.bioconjchem.8b00156.

129. Lai SK, Wang YY, Hanes J. Mucus-penetrating nanoparticles for drug and gene delivery to mucosal tissues. Adv Drug Deliv Rev. 2009;61(2):158-71. https://doi.org/10.1016/j.addr.2008.11.002.

130. Tang BC, Dawson M, Lai SK, Wang YY, Suk JS, Yang M, et al. Biodegradable polymer nanoparticles that rapidly penetrate the human mucus barrier. Proc Natl Acad Sci U S A. 2009;106(46):19268-73. https://doi.org/10.1073/pnas.0905998106.

131. Suk JS, Lai SK, Boylan NJ, Dawson MR, Boyle MP, Hanes J. Rapid transport of muco-inert nanoparticles in cystic fibrosis sputum treated with $\mathrm{N}$-acetyl cysteine. Nanomedicine (Lond). 2011;6(2):365-75. https://doi.org/10.2217/nnm.10.123.

132. Ensign LM, Schneider C, Suk JS, Cone R, Hanes J. Mucus penetrating nanoparticles: biophysical tool and method of drug and gene delivery. Adv Mater. 2012;24(28):3887-94. https://doi. org/10.1002/adma.201201800.

133. $\mathrm{Cu}$ Y, Saltzman WM. Controlled surface modification with poly(ethylene)glycol enhances diffusion of PLGA nanoparticles in human cervical mucus. Mol Pharm. 2009;6(1):173-81. https:// doi.org/10.1021/mp8001254.

134. Wang YY, Lai SK, Suk JS, Pace A, Cone R, Hanes J. Addressing the PEG mucoadhesivity paradox to engineer nanoparticles that "slip" through the human mucus barrier. Angew Chem Int Ed Engl. 2008;47(50):9726-9. https://doi.org/10.1002/anie.200803526.

135. Forier K, Messiaen AS, Raemdonck K, Deschout H, Rejman J, De Baets F, et al. Transport of nanoparticles in cystic fibrosis sputum and bacterial biofilms by single-particle tracking microscopy. Nanomedicine (Lond). 2013;8(6):935-49. https:// doi.org/10.2217/nnm.12.129.

136. Sigurdsson HH, Kirch J, Lehr CM. Mucus as a barrier to lipophilic drugsInt J Pharm. 2013;453(1):56-64. https://doi. org/10.1016/j.ijpharm.2013.05.040.

137. Messiaen AS, Forier K, Nelis H, Braeckmans K, Coenye T. Transport of nanoparticles and tobramycin-loaded liposomes in Burkholderia cepacia complex biofilms. PloS One. 2013;8(11):e79220. https://doi.org/10.1371/journal.pone.0079220.

138. Zhang Z, Tan S, Feng SS. Vitamin E TPGS as a molecular biomaterial for drug delivery. Biomaterials. 2012;33(19):4889-906. https://doi.org/10.1016/j.biomaterials.2012.03.046.

139. Guo Y, Luo J, Tan S, Otieno BO, Zhang Z. The applications of Vitamin E TPGS in drug delivery. Eur J Pharm Sci. 2013;49(2):175-86. https://doi.org/10.1016/j.ejps.2013.02.006.

140. Dahe GJ, Kadam SS, Sabale SS, Kadam DP, Sarkate LB, Bellare JR. In vivo evaluation of the biocompatibility of surface modified hemodialysis polysulfone hollow fibers in rat. PloS One. 2011;6(10):e25236. https://doi.org/10.1371/journal.pone.0025236.

141. Tielen P, Rosenau F, Wilhelm S, Jaeger KE, Flemming HC, Wingender J. Extracellular enzymes affect biofilm formation of mucoid Pseudomonas aeruginosa. Microbiology. 2010;156(Pt 7):2239-52. https://doi.org/10.1099/mic.0.037036-0.

142. Kozirog A, Otlewska A, Brycki B. Viability, enzymatic and protein profiles of pseudomonas aeruginosa biofilm and planktonic cells after monomeric/gemini surfactant treatment. Molecules. 2018;23(6). https://doi.org/10.3390/molecules23061294.

143. Radovic-Moreno AF, Lu TK, Puscasu VA, Yoon CJ, Langer R, Farokhzad OC. Surface charge-switching polymeric nanoparticles for bacterial cell wall-targeted delivery of antibiotics. ACS nano. 2012;6(5):4279-87.

144. Liu Y, Busscher HJ, Zhao B, Li Y, Zhang Z, van der Mei HC, et al. Surface-adaptive, antimicrobially loaded, micellar nanocarriers with enhanced penetration and killing efficiency in staphylococcal biofilms. ACS nano. 2016;10(4):4779-89. https://doi. org/10.1021/acsnano.6b01370.

145. Horev B, Klein MI, Hwang G, Li Y, Kim D, Koo H, et al. pHactivated nanoparticles for controlled topical delivery of farnesol to disrupt oral biofilm virulence. ACS nano. 2015;9(3):2390-404.

146. Tan S, Li X, Guo Y, Zhang Z. Lipid-enveloped hybrid nanoparticles for drug delivery. Nanoscale. 2013;5(3):860-72. https://doi. org/10.1039/c2nr32880a.

147. Cheow WS, Chang MW, Hadinoto K. The roles of lipid in anti-biofilm efficacy of lipid-polymer hybrid nanoparticles encapsulating antibiotics. Colloids Surf A Physicochem Eng Asp. 2011;389(1-3):158-65. https://doi.org/10.1016/j.colsurfa. 2011.08.035.

148. Baek J-S, Tan CH, Ng NKJ, Yeo YP, Rice SA, Loo SCJ. A programmable lipid-polymer hybrid nanoparticle system for localized, sustained antibiotic delivery to Gram-positive and Gramnegative bacterial biofilms. Nanoscale Horiz. 2018. https://doi. org/10.1039/c7nh00167c.

149. Cheow WS, Hadinoto K. Lipid-polymer hybrid nanoparticles with rhamnolipid-triggered release capabilities as anti-biofilm drug delivery vehicles. Particuology. 2012;10:327-33.

150. Angsantikul P, Thamphiwatana S, Zhang Q, Spiekermann K, Zhuang J, Fang RH, et al. Coating nanoparticles with gastric epithelial cell membrane for targeted antibiotic delivery against Helicobacter pylori infection. Adv Ther. 2018;1(2):1800016. https://doi.org/10.1002/adtp.201800016.

151. González-Alvarez M, González-Alvarez I, Bermejo M. Hydrogels: an interesting strategy for smart drug delivery. Ther Deliv. 2013;4(2):157-60. https://doi.org/10.4155/tde.12.142.

152. Hoare TR, Kohane DS. Hydrogels in drug delivery: progress and challenges. Polymer. 2008;49(8):1993-2007. https://doi. org/10.1016/j.polymer.2008.01.027.

153. Hamidi M, Azadi A, Rafiei P. Hydrogel nanoparticles in drug delivery. Adv Drug Deliv Rev. 2008;60(15):1638-49. https:// doi.org/10.1016/j.addr.2008.08.002.

154. Kabanov AV, Vinogradov SV. Nanogels as pharmaceutical carriers: finite networks of infinite capabilities. Angew Chem Int Ed Engl. 2009;48(30):5418-29. https://doi.org/10.1002/ anie. 200900441.

155. Oh JK, Siegwart DJ, Matyjaszewski K. Synthesis and biodegradation of nanogels as delivery carriers for carbohydrate drugs. Biomacromolecules. 2007;8(11):3326-31. https://doi. org/10.1021/bm070381+.

156. Hallworth GW, Westmoreland DG. The twin impinger: a simple device for assessing the delivery of drugs from metered dose pressurized aerosol inhalers. J Pharm Pharmacol. 1987;39(12):966-72. https://doi.org/10.1111/j.2042-7158.1987. tb03142.x. 
157. Fang Y, Lou M-m, Li B, Xie G-L, Wang F, Zhang L-X et al. Characterization of Burkholderia cepacia complex from cystic fibrosis patients in China and their chitosan susceptibility. World J Microbiol Biotechnol. 2010;26(3):443-50. https://doi. org/10.1007/s11274-009-0187-z.

158. Chávez de Paz LE, Resin A, Howard KA, Sutherland DS, Wejse PL. Antimicrobial effect of chitosan nanoparticles on streptococcus mutans biofilms. Appl Environ Microbiol. 2011;77(11):3892-5. https://doi.org/10.1128/aem.02941-10.

159. Rabea EI, Badawy ME, Stevens CV, Smagghe G, Steurbaut W. Chitosan as antimicrobial agent: applications and mode of action. Biomacromolecules. 2003;4(6):1457-65. https://doi. org $/ 10.1021 / \mathrm{bm} 034130 \mathrm{~m}$.

160. das Neves J, Bahia MF, Amiji MM, Sarmento B. Mucoadhesive nanomedicines: characterization and modulation of mucoadhesion at the nanoscale. Expert Opin Drug Deliv. 2011;8(8):1085104. https://doi.org/10.1517/17425247.2011.586334.

161. Chen EY, Wang YC, Chen CS, Chin WC. Functionalized positive nanoparticles reduce mucin swelling and dispersion. PloS One. 2010;5(11):e15434. https://doi.org/10.1371/journal. pone. 0015434

162. Huang JX, Blaskovich MA, Pelingon R, Ramu S, Kavanagh A, Elliott AG, et al. Mucin binding reduces colistin antimicrobial activity. Antimicrob Agents Chemother. 2015;59(10):5925-31. https://doi.org/10.1128/aac.00808-15.

163. Buonpensiero P, De Gregorio F, Sepe A, Di Pasqua A, Ferri $\mathrm{P}$, Siano M, et al. Hyaluronic acid improves "pleasantness" and tolerability of nebulized hypertonic saline in a cohort of patients with cystic fibrosis. Adv Ther. 2010;27(11):870-8. https://doi.org/10.1007/s12325-010-0076-8.

164. Ros M, Casciaro R, Lucca F, Troiani P, Salonini E, Favilli F, et al. Hyaluronic acid improves the tolerability of hypertonic saline in the chronic treatment of cystic fibrosis patients: a multicenter, randomized, controlled clinical trial. J Aerosol Med Pulm Drug Deliv. 2014;27(2):133-7. https://doi.org/10.1089/ jamp.2012.1034.

165. Montanari E, Di Meo C, Coviello T, Gueguen V, Pavon-Djavid G, Matricardi P. Intracellular delivery of natural antioxidants via hyaluronan nanohydrogels. Pharmaceutics. 2019;11(10). https://doi.org/10.3390/pharmaceutics11100532.

166. Huang Z, Zhou T, Yuan Y, Natalie Kłodzińska S, Zheng $\mathrm{T}$, Sternberg C, et al. Synthesis of carbon quantum dot-poly lactic-co-glycolic acid hybrid nanoparticles for chemo-photothermal therapy against bacterial biofilms. J Colloid Interf Sci. 2020;577:66-74. https://doi.org/10.1016/j.jcis.2020.05.067.

167. Wan F, Bohr A, Maltesen MJ, Bjerregaard S, Foged C, Rantanen J, et al. Critical solvent properties affecting the particle formation process and characteristics of celecoxibloaded PLGA microparticles via spray-drying. Pharm Res. 2013;30(4):1065-76. https://doi.org/10.1007/s11095012-0943-x.

168. Wan F, Larsen FH, Bordallo HN, Foged C, Rantanen J, Yang M. Insight into nanoscale network of spray-dried polymeric particles: role of polymer molecular conformation. ACS Appl Mater Interfaces. 2018;10(43):36686-92. https://doi. org/10.1021/acsami.8b12475.

169. Ristic BZ, Milenkovic MM, Dakic IR, Todorovic-Markovic BM, Milosavljevic MS, Budimir MD, et al. Photodynamic antibacterial effect of graphene quantum dots. Biomaterials. 2014;35(15):4428-35. https://doi.org/10.1016/j.biomaterials. 2014.02.014
170. Craig WA. Choosing an antibiotic on the basis of pharmacodynamics. Ear Nose Throat J. 1998;77(6 Suppl):7-11; discussion -2.

171. Mukker JK, Singh RS, Derendorf H. Pharmacokinetic and pharmacodynamic implications in inhalable antimicrobial therapy. Adv Drug Deliv Rev. 2015;85:57-64. https://doi. org/10.1016/j.addr.2015.03.002.

172. Morey M, Pandit A. Responsive triggering systems for delivery in chronic wound healing. Adv Drug Deliv Rev. 2018;129:16993. https://doi.org/10.1016/j.addr.2018.02.008.

173. Mura S, Nicolas J, Couvreur P. Stimuli-responsive nanocarriers for drug delivery. Nat Mater. 2013;12:991. https://doi. org/10.1038/nmat3776.

174. Riley T, Christopher D, Arp J, Casazza A, Colombani A, Cooper A, et al. Challenges with developing in vitro dissolution tests for orally inhaled products (OIPs). AAPS PharmSciTech. 2012;13(3):978-89. https://doi.org/10.1208/s12249012-9822-3.

175. Gray V, Hickey A, Balmer P, Davies NM, Dunbar C, Foster T et al., editors. The Inhalation Ad Hoc Advisory Panel for the USP Performance Tests of Inhalation Dosage Forms2008.

176. Cingolani E, Alqahtani S, Sadler RC, Prime D, Stolnik S, Bosquillon $\mathrm{C}$. In vitro investigation on the impact of airway mucus on drug dissolution and absorption at the air-epithelium interface in the lungs. Eur J Pharm Biopharm. 2019;141:210-20. https://doi.org/10.1016/j.ejpb.2019.05.022.

177. Zhang B, Korolj A, Lai BFL, Radisic M. Advances in organ-ona-chip engineering. Nat Rev Mater. 2018;3(8):257-78. https:// doi.org/10.1038/s41578-018-0034-7.

178. Hajipouran Benam K, Villenave R, Lucchesi C, Mazur M, Hamilton G, Ingber D. Development of a human COPD modelon-a-chip to mimic disease exacerbation (a small airway-on-achip model). Eur Respir J. 2014;44(Suppl 58):P3340.

179. Benam KH, Villenave R, Lucchesi C, Varone A, Hubeau C, Lee $\mathrm{HH}$, et al. Small airway-on-a-chip enables analysis of human lung inflammation and drug responses in vitro. Nat Methods. 2016;13(2):151-7. https://doi.org/10.1038/nmeth.3697.

180. Hajipouran Benam K, Novak R, Villenave R, Lucchesi C, Hubeau C, Nawroth J et al. Human small airway-on-a-chip: A novel microphysiological system to model lung inflammation, accelerate drug development and enable inhalational toxicoanalysis. Eur Respir J. 2016;48(suppl 60):OA4542. https://doi. org/10.1183/13993003.congress-2016.OA4542.

181. Bohr A, Water J, Beck-Broichsitter M, Yang M. Nanoembedded microparticles for stabilization and delivery of drug-loaded nanoparticles. Curr Pharm Des. 2015;21(40):5829-44. https:// doi.org/10.2174/1381612821666151008124322.

182. Anton N, Jakhmola A, Vandamme TF. Trojan microparticles for drug delivery. Pharmaceutics. 2012;4(1):1-25. https://doi. org/10.3390/pharmaceutics4010001.

Publisher's Note Springer Nature remains neutral with regard to jurisdictional claims in published maps and institutional affiliations. 